Portland State University

PDXScholar

$1-1-2011$

\title{
Is Decoding Sufficient to Predict Reading Ability in Kindergarten Through 2nd Grade Students?
}

Deborah Adkins

Portland State University

Follow this and additional works at: https://pdxscholar.library.pdx.edu/open_access_etds Let us know how access to this document benefits you.

\section{Recommended Citation}

Adkins, Deborah, "Is Decoding Sufficient to Predict Reading Ability in Kindergarten Through 2nd Grade Students?" (2011). Dissertations and Theses. Paper 178.

https://doi.org/10.15760/etd.178

This Thesis is brought to you for free and open access. It has been accepted for inclusion in Dissertations and Theses by an authorized administrator of PDXScholar. Please contact us if we can make this document more accessible: pdxscholar@pdx.edu. 
Is Decoding Sufficient to Predict Reading Ability in Kindergarten Through $2^{\text {nd }}$ Grade Students?

by

Deborah Adkins

A thesis submitted in fulfillment of the requirements for the degree of

\section{Master of Science \\ in \\ Systems Science}

Thesis Committee:

Wayne Wakeland, Chair

Susan Lenski

Martha McCall

Portland State University

(C)2011 


\begin{abstract}
This research considers the predictive utility of 10 decoding skills on a student's ability to read. The 10 skills are Consonant Blends/Digraphs, Decode Multi-Syllable Words, Decode Patterns/Word Families, Letter Identification, Manipulation of Sounds, Matching Letters to Sounds, Phoneme Identification, Phonological Awareness, Syllable Types: CVC, CVCe, R-Control, and Vowel Digraphs/Diphthongs. The research also examines the nature of the relationships between the decoding skills and reading ability. Furthermore, the research decomposes reading ability into segment 1 assessing decoding, and segment 2, assessing comprehension. Specifically, the study assesses the manner in which each of the 10 skills contributes to the variance in the two segment scores.
\end{abstract}

The literature is limited to efficacy studies related to programs used to teach reading, and prior studies addressing skills have failed to extend examination beyond correlations between phonological and phonemic awareness, and a student's ability to read. These issues were examined in the present research using assessment records of 541 kindergarten, first, and second grade students who had each been administered the 10 aforementioned decoding skills tests as well as a reading assessment administered in two parts (decoding and comprehension). All records reflected assessments occurring within the same school year for each student assessed. The dependent variables are scaled scores with a valid range from 100 to 350 and represent the combined reading score plus each of the two segment scores. Multiple regression analysis was employed to consider the predictive utility and examine the correlations between the variables. Hierarchical 
regression was employed to further scrutinize the variance accounted for by each decoding skill.

As a group, the 10 decoding skills indicated that students scoring higher overall on decoding also scored higher on overall reading ability, segment 1 , and segment $2(p<$ .001). However, the coefficient of variation indicates the grouped decoding skills may not be useful for prediction purposes for the segment 1 assessment $(\mathrm{CV}=.103)$. Correlations between all independent variables and the dependent variables were moderate to high (.617 to .880), with the exception of Letter Identification and Matching Letters to Sounds which were low to moderate (.248 to .500$)$. The correlation between Letter Identification and Matching Letters to Sounds was moderate (.579). Post hoc analysis indicated the inclusion of Letter Identification and Matching Letters to Sounds did not account for any statistically significant additional variance in the combined reading score $(p=.459)$, the segment 1 score $(p=.261)$, nor in the segment 2 score

$(p=.749)$.

By itself decoding does not sufficiently predict reading ability. This study brings to light the nature of the relationship between discrete decoding skills and reading ability for early learners. The research identifies additional information for consideration by educators providing early literacy instruction which may help them zero in on difficulties students may be having as they advance in their literacy. 


\section{Table of Contents}

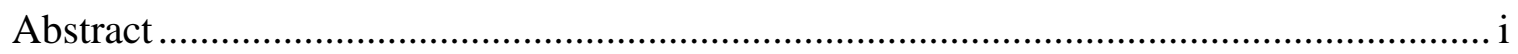

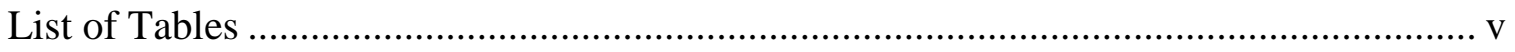

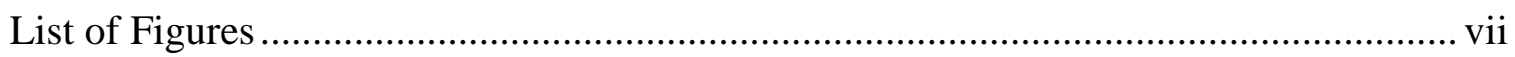

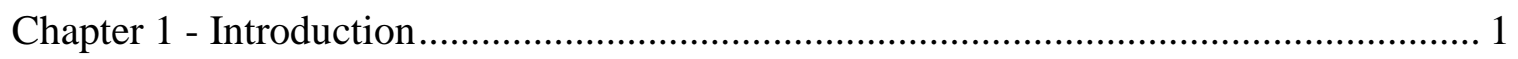

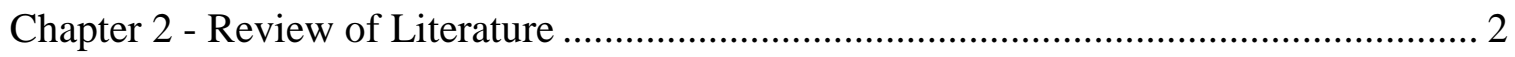

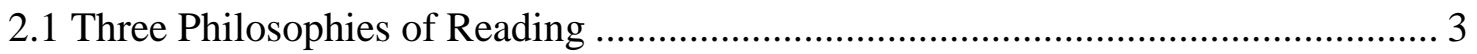

2.1.1 Bottom Up ……………………............................................................. 3

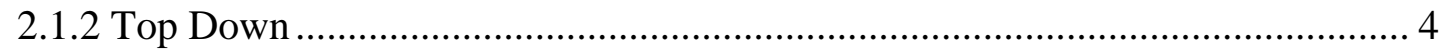

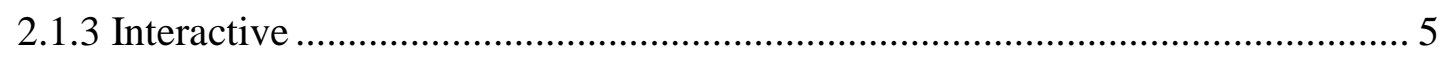

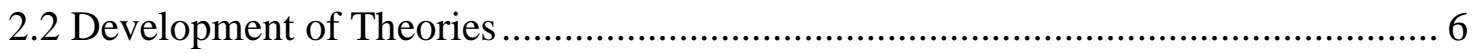

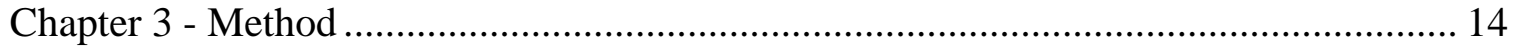

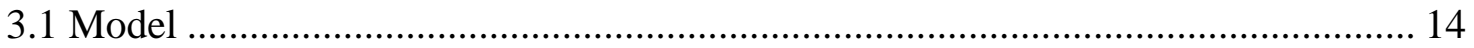

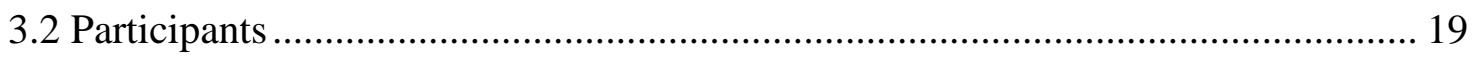

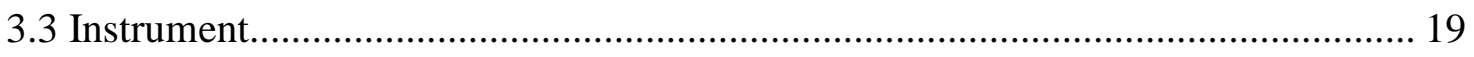

3.3.1 Skills Checklist Tests............................................................................... 19

3.3.2 Survey with Goals Tests ................................................................................. 24

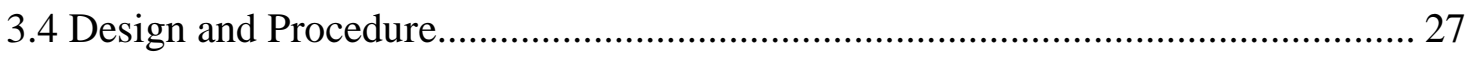

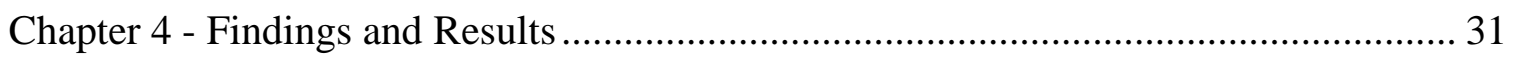


4.2 Regressing the Combined MPG Reading Score on the 10 Skills Checklist Scores 34

4.2.1 Summary of Regression Results 46

4.3 Regressing the Segment 1 Reading Score (PhonAware, Phonic, ConPrnt) on the 10 Skills Checklist Scores 48

4.4 Regressing the Segment 2 Reading Score (Vocab, Comprehen, Writing) on the 10 Skills Checklist Scores .............................................................................. 51

4.5 Hierarchical Regression .......................................................................... 55

4.5.1 Combined Reading Survey with Goals RIT Score ..................................... 55

4.5.2 Segment 1 Reading Score (PhonAware, Phonic, ConPrnt) ............................ 59

4.5.3 Segment 2 Reading Score (Vocab, Comprehen, Writing)............................. 61

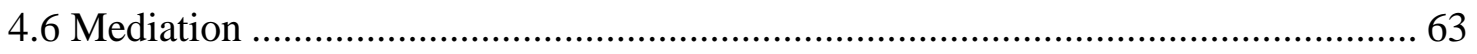

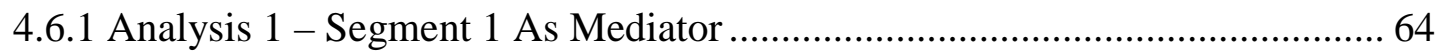

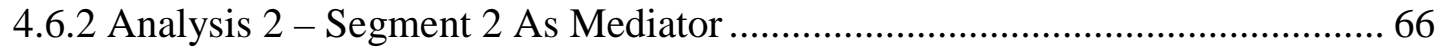

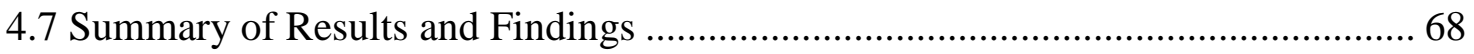

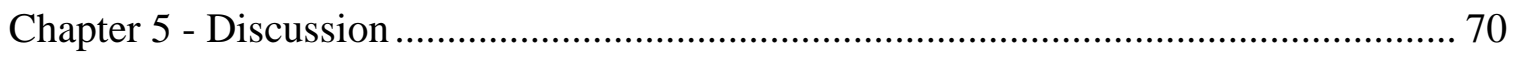

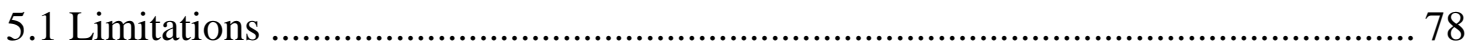

5.2 Implications for Future Research .............................................................. 79

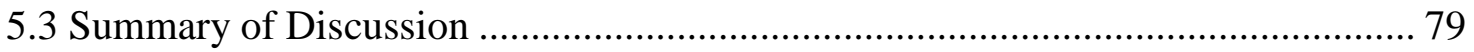

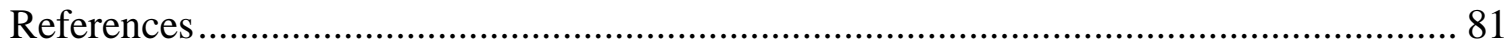




\section{List of Tables}

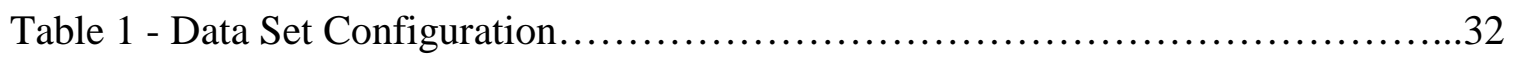

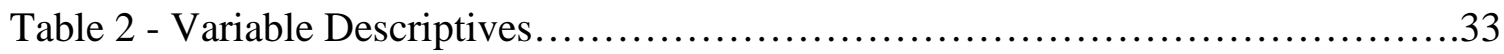

Table 3 - Reading RIT Scores Beginning of School Year...........................33

Table 4 - Reading RIT Scores Middle of School Year...............................33

Table 5 - Reading RIT Scores End of School Year................................. 33

Table 6 - Variability Accounted for in RIT Score.................................. 36

Table 7 - Descriptive Statistics for LI and MLtS............................... 37

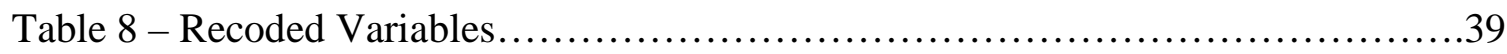

Table 9 - Correlations Between Variables....................................43

Table 10 - Coefficients Table..............................................44

Table 11 - Model Summary Table................................................44

Table 12 - ANOVA......................................................45

Table 13 - Strength of Predictor Controlling for Other Predictors $\ldots . \ldots \ldots \ldots \ldots \ldots \ldots \ldots . . .47$

Table 14 - Comparison of Correlations.........................................48

Table 15 - Coefficients Table.............................................49

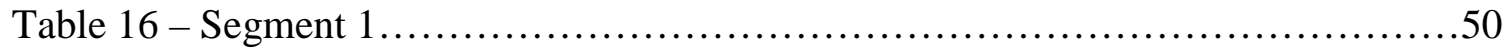

Table 17 - Combined Reading Assessment.....................................50

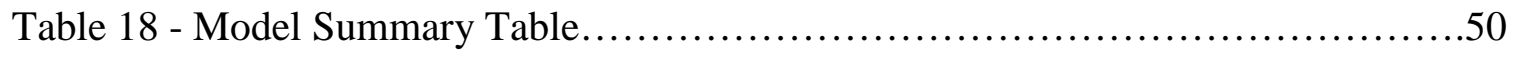

Table 19 - ANOVA......................................................50

Table 20 - Comparison of Correlations.........................................52

Table 21 - Coefficients Table..............................................52

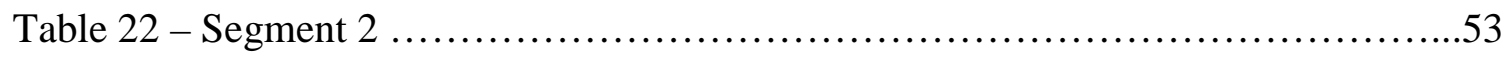




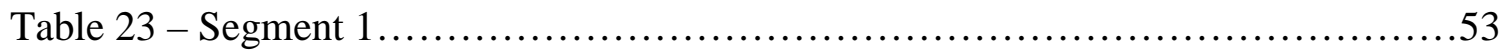

Table 24 - Combined Reading Assessment........................................53

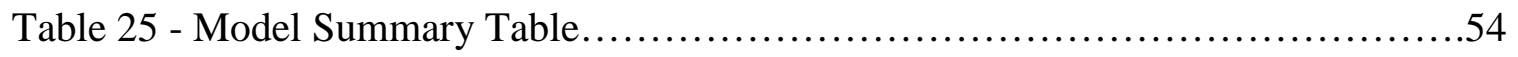

Table 26 - ANOVA........................................................... 54

Table 27 - Model Summary..................................................57

Table 28 - Model Summary ..............................................59

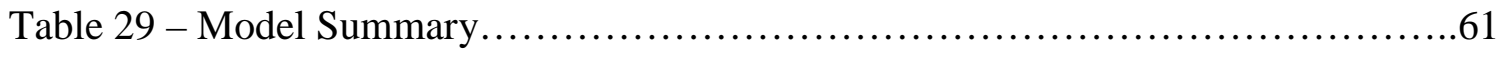

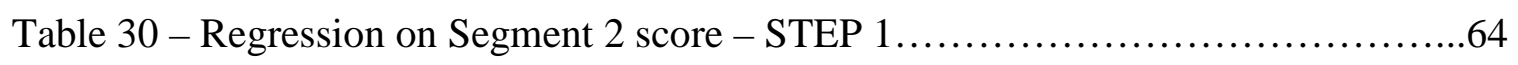

Table 31 - Regression on Segment 1 score - STEP 2 ...........................64

Table 32 - Regression on Segment 2 with Segment 1 - STEP 3.....................65

Table 33 - Regression on Segment 2 score with PA, PI, and Segment1 - STEP 4......65

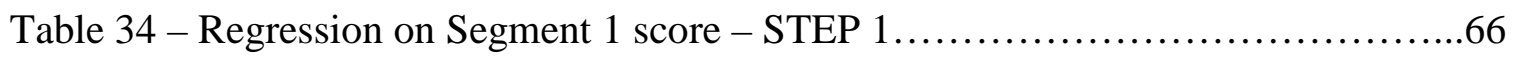

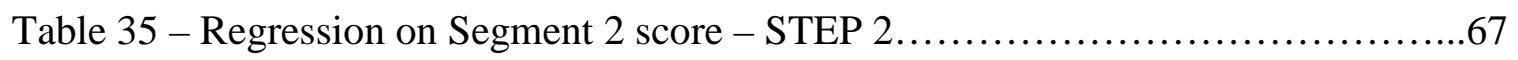

Table 36 - Regression on Segment 1 with Segment 2 - STEP $3 \ldots \ldots \ldots \ldots \ldots \ldots \ldots \ldots . \ldots 6$

Table 37 - Regression on Segment 1 score with PA, PI, and Segment2 - STEP 4......67 


\section{List of Figures}

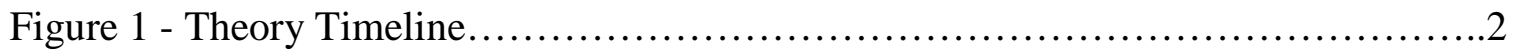

Figure 2 - Bottom Up Hierarchy.............................................

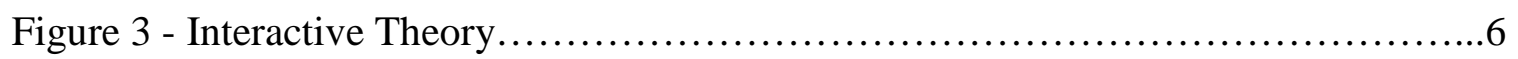

Figure 4 - Does Decoding Predict Reading?............................................................ 13

Figure 5 - Mediation....................................................... 15

Figure 6 - Regressing Segment 2 on 10 Discrete Decoding Skills...................16

Figure 7 - Regressing Segment 1 on 10 Discrete Decoding Skills....................17

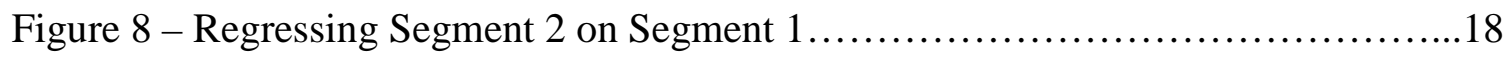

Figure 9 - Segment 1 Mediating the Effect of the Decoding Skills on Segment 2.......18

Figure 10 - Regressing the 10 skills checklist tests on the separate Segment (decoding \&

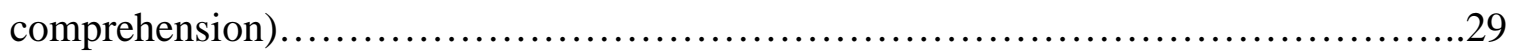

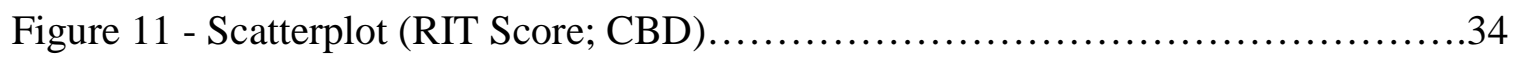

Figure 12 - Scatterplot (RIT Score; DPWF).................................. 34

Figure 13 - Scatterplot (RIT Score; DMSW) .......................................

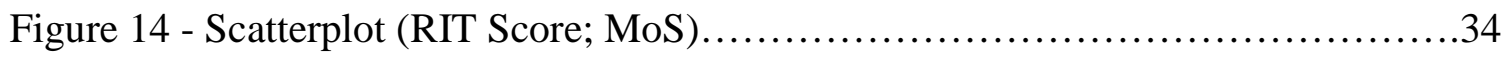

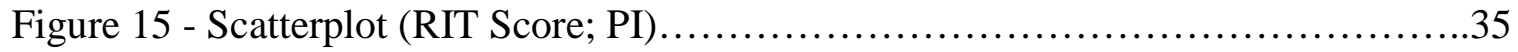

Figure 16 - Scatterplot (RIT Score; PA) .................................... 35

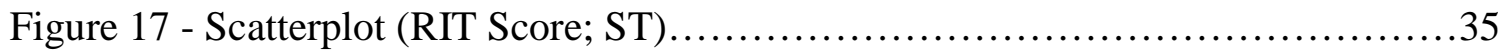

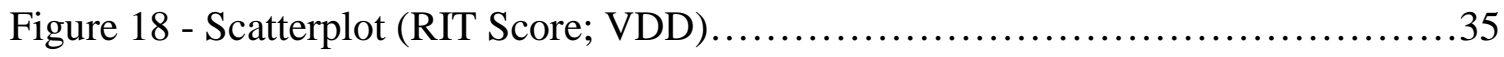

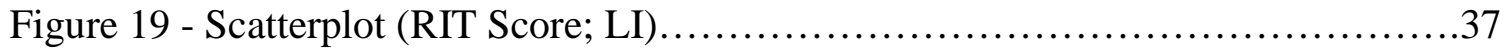

Figure 20 - Scatterplot (RIT Score; MLtS) ......................................

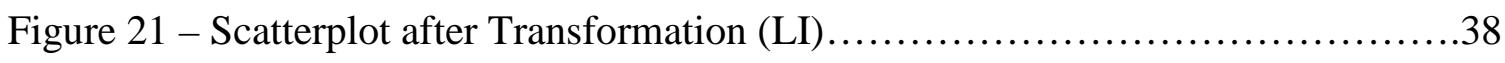




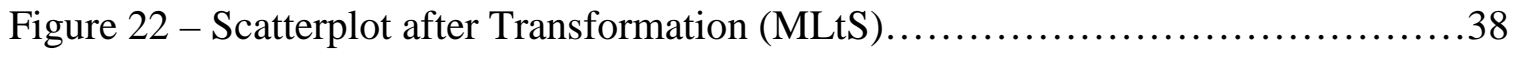

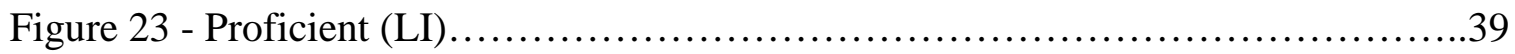

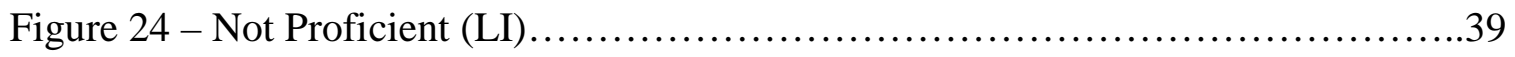

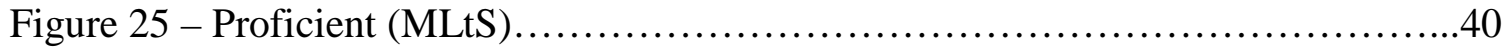

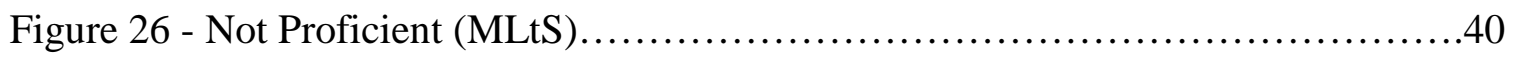

Figure 27 - Not Proficient on both LI and MLtS ..............................40

Figure 28 - Regression Residuals for RIT Score...............................41

Figure 29 - Scatterplot of Residuals.......................................41

Figure 30 - P-Plot of Regression Residuals..................................42

Figure 31 - Hierarchical Regression on Combined MPG Reading Survey with Goals

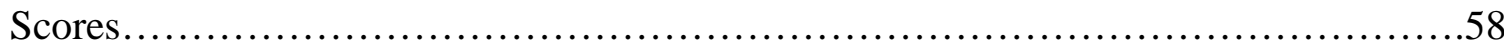

Figure 32 -Hierarchical Regression on Segment 1 Scores (PhonAware, Phonic,

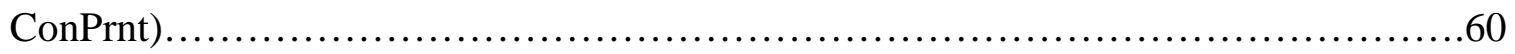

Figure 33 - Hierarchical Regression on Segment 2 Scores (Comprehen, Vocab,

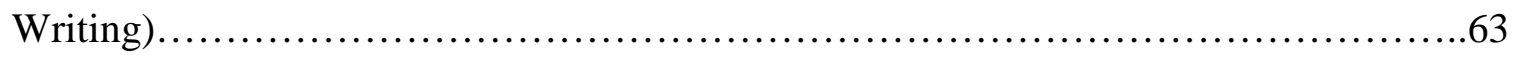

Figure 34 - Improperly Reported Variance Accounted for in Reading Scores...........74

Figure 35 - Variance Accounted for in Reading Scores (with correlation taken into

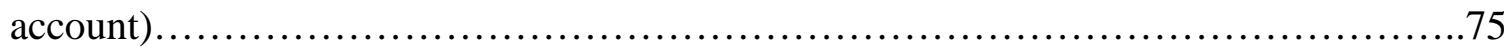


Introduction

\section{Chapter 1 - Introduction}

What is reading and how do you measure reading ability? In 1997, The National Reading Panel (NRP) was assembled by the Director of the National Institute of Child Health and Human Development (NICHD) in consultation with the Secretary of Education, to provide a report on research assessing the effectiveness of various approaches to teaching children to read. Absent from the final report, Teaching Children to Read: An Evidence-Based Assessment of the Scientific Research Literature On Reading and Its Implications for Reading Instruction, was a concise definition of 'reading'. The panel did however provide general guidelines in the form of 'essential components to reading success.' These necessary components were defined as explicit and systematic instruction in phonemic awareness, phonics, vocabulary, fluency, and comprehension (NRP 2000). Is it prudent to elect a course of instructional action lacking a clear understanding of the issue you hope to address? So what is reading? The answer is contingent upon your perspective. 


\section{Chapter 2 - Review of Literature}

This paper provides a review of the literature in conjunction with a timeline on attitudes in academia regarding what constitutes reading, how best to instruct students, and how to assess success in this domain. Three overarching philosophies have emerged over time with slightly different definitions of reading.

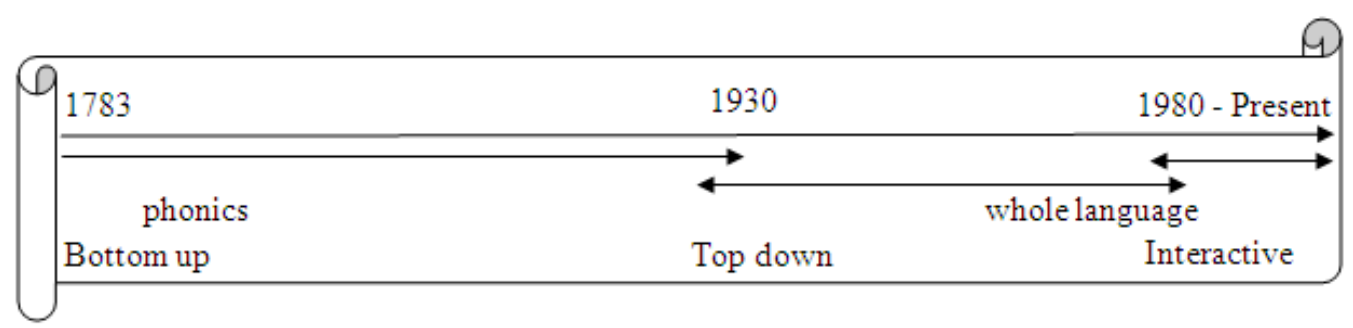

Figure 1 - Theory Timeline

These three philosophies represent the progression of a theory as perspectives have matured. Numerous theoretically based publications provide support to their corresponding views. Far fewer qualitative and quantitative studies offer empirical data as evidence prior to the 1980's, in part; this is a result of the developing governance structure from school to district and more recently the federal government. Beginning in the 1980s, empirical studies have been supported by the great strides in our ability to collect, store, and aggregate data in which technology has played a pivotal role. 


\subsection{Three Philosophies of Reading}

\section{$\underline{\text { 2.1.1 Bottom Up }}$}

From the colonial period through the early 1900s the bottom-up approach, codeemphasis/phonics, to teaching reading was utilized (Chall 1997). This method provided early instruction in learning the alphabet and the relationship between letters and sounds as well as reading connected text. If you subscribe to the part-to-whole or bottom-up approach to reading you may define reading as the ability to sound out and identify the meanings of words which will in turn aid in understanding of sentences and then paragraphs (Braunger \& Lewis 2006). The aforementioned is a skills-based approach to reading with decoding at the core of these basic skills. Subscribers to this line of thinking dismiss

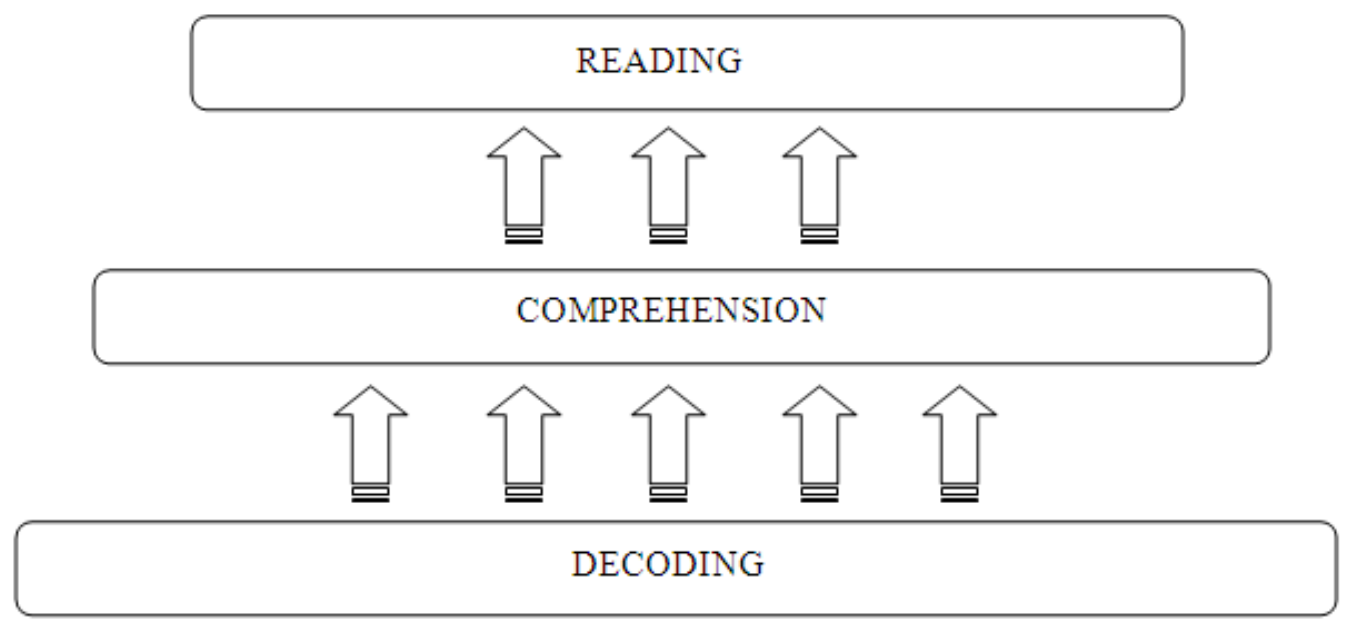

Figure 2 - Bottom Up Hierarchy 
Additionally, student learning under this model is hierarchical indicating mastery at lower level skills is necessary and sufficient prior to the introduction of higher level skills (Stanovich 1980).

\subsubsection{Top Down}

Around the 1920s a top-down approach referred to as sight/whole-word methods emerged and perpetuated into the 1960s (Chall 1997). Initially these methods were taught using common reading books, called basal readers. Basal readers were publications used as the basis for lessons to teach children reading skills. The format of these readers reflected the current theory of how students learn to read. Educators and researchers subscribing to this approach to reading indicate that students bring their knowledge of the world to the text and develop decoding skills as a result of reading for meaning (Braunger \& Lewis 2006). A similar top-down method, the Language Experience Approach, was evaluated at this time as well.

Reintroduction to an emphasis on phonics in the late 1960s and through the 1970s fueled controversy among experts in the field. Jeanne Chall provides a fairly ${ }^{1}$ comprehensive account of the research contributing to the controversy in the third

\footnotetext{
${ }^{1}$ The account provided by Chall is incomplete due to her omission of a follow up study by Currier 1923 (supports a mix of methods) that qualifies the conclusion of Currier \& Duguid's 1916 study (supports topdown) to which Chall refers. The 1923 study provides important insight regarding research leading to change in educational practices.
} 
addition of her book, Learning to Read: The Great Debate. The response from the topdown cohort was what has been referred to by purist supporters as a "grass-roots" movement and termed whole language or literature based programs that were reintroduced in the 1980s asserting word recognition and phonics are natural outcomes of connected reading and did not require direct teaching of these skills (Goodman 1987, Watson 1989). Support for the whole language movement persisted well into the 1990s.

\section{$\underline{\text { 2.1.3 Interactive }}$}

During the time period from the late 1970s to the early 1980s we began to see intentional concentration around a theory encompassing aspects of both bottom-up and top-down approaches. The interactive approach is a modified hybrid of the bottom-up and top-down approaches, absent the constraint of hierarchy and including a compensatory assumption (Stanovich 1980), where it is asserted that both the reader and the text contribute to the process of comprehension. Supporters of this theory define reading as the process of constructing meaning as the reader interacts with various cueing systems available within the text (Braunger \& Lewis 2006, Moats 2000, Weaver 2002). 


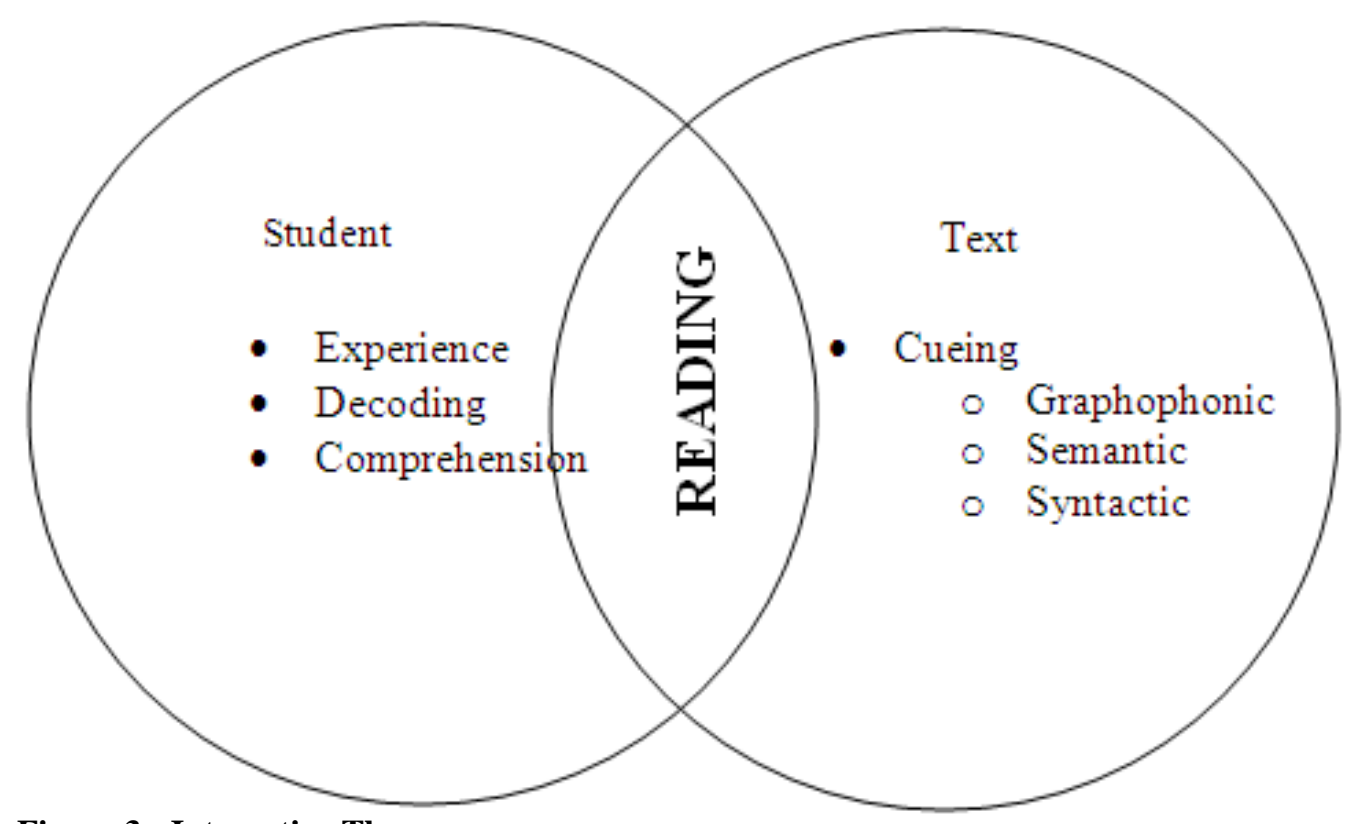

Figure 3 - Interactive Theory

\subsection{Development of Theories}

The following represents progression within the three aforementioned

philosophies. One of the earliest programs based on a bottom-up approach was as a result of a publication authored by Noah Webster. Published in 1783, The American Spelling Book ("Noah Webster," 2010) was among the first colonial, as opposed to British, publications targeting American school children. This was the text that became widely used for instruction at the time. It contained polysyllabic words broken into individual syllables as well as precepts and fables (“Noah Webster," 2010), which may have been part of the allure. It was revised several times over the years and became known as Webster's Blue Back Speller (Chall 1997). The intended audience of Webster's 
time included children of varying age and ability, taught together, in one-room school houses.

As the bottom-up approach to the theory of reading progressed, researchers began to examine the dynamics that may contribute to reading ability. Dolch and Bloomster (1937) attempt to ascertain when a child is ready to learn phonics. The authors assert that it takes higher mental ability, or at least a different type of mental processing, to be ready to learn phonics. The results of their study using first and second graders indicate that students with a mental age/ability below seven years seem to be the minimum age for phonic readiness. They indicate that most students reach a mental age of seven years by second grade.

By 1974 researchers again attempt to refine the bottom-up approach by describing learning to read as moving through a series of processing stages from visual to phonological and episodic memory systems until the student comprehends what has been read. A student's ability is measured on two criteria, accuracy and automaticity. Accuracy is whether or not the student got it right regardless of the time it took to respond and automaticity is measured by the student's ability to respond quickly while maintaining accuracy (LaBerge and Samuels 1974).

The top-down approach went through a similar metamorphosis. In 1916 educators Lillian Currier and Olive Duguid questioned the efficacy of programs using phonic drills. They divided their first and second grade classes into two groups each. One group from 
each grade received curriculum including phonic drills while the other group's curriculum did not. At the end of the school year they found no difference in reading ability between the two groups. Additionally, they found the phonic drills' group seemed fatigued with a tendency to disengage as a result of the drills. However, they reported special cases where the drills did seem to be beneficial.

By the 1930s and through the 1970s the top-down approach to reading had gained much support in the way of basal or basic readers (e.g. Fun with Dick and Jane). As such studies between programs that were phonics based versus those that employed basic readers began to emerge. Elmer Morgan and Morton Light conducted such a study. They compared the scores of third grade students from four independent school populations, over a three year period. Programs began in first grade where two groups participated in a Phonetic Keys to Reading program while the other two groups participated in a Basic Reading program. The analysis was conducted using the reading scores of the same students once they reached grade three. The results indicated that the phonetic approach was not superior to the basic, nor did the scores indicate it to be detrimental.

Moving into the late 1970s and early 1980s brought about a more stringent model of the top-down approach, Whole Language. Whole language purists maintain that whole language is not practice nor is it a method; rather it is a belief system. It is about constructing meaning not getting/saying the word (Goodman \& Goodman 1976; K. Goodman 1987, 1989; Altwerger, Edelsky, \& Flores 1987). Much of the literature on 
whole language from the purist perspective provides no empirical evidence as support. Instead generalizations are made regarding the relationship between oral and written language being analogous to the relationship between natural language and literacy. As such the following synthesis by Steven Stahl and Patricia Miller of whole language and language experience approaches for beginning readers is not reflective of whole language in its purist form.

Stahl and Miller cite quantitative studies indicating no significant differences in the number of oral reading miscues, nor in the measure of retelling, produced by whole language, language experience trained, and basal trained first graders. They state that no significant differences were found in achievement from standardized tests or in attitude of students toward reading amongst the three. It was interesting that the authors concluded that overall the three approaches/theories fared similarly but that in some of the studies whole language seemed to be more effective for word recognition (getting the words, something that purists indicate is not the purpose) rather than comprehension (comprehension being the focus of this theory) for kindergarteners or when used instead of reading readiness programs.

Presently, the interactive approach is the generally accepted theory associated with what reading is. The International Reading Association asserts that the research indicates there exists no single instructional program that is effective for all students (Braunger and Lewis 2006). Lillian Currier came to this same conclusion 83 years prior 
in 1923 after completing a follow-up study based on special case circumstances found in a 1916 study she conducted with fellow educator Olive Duguid. She began her follow-up study the year after their initial study was completed. She identified four groups of students.

Groupl comprised grade three students who she termed "bright kids." She modified the phonic drills that appeared not to work with students who seemed to have command of phonemic awareness and used pronunciation games where she selected vocabulary from the dictionary that she believed would be challenging for this group of students. The effect was that students remained engaged, vocabulary increased, and they exhibited greater confidence in attacking unfamiliar words in both sight $\&$ silent reading.

Group2 was also comprised of grade three students which she referred to as "careless, heedless, inattentive readers." As with group1 she used pronunciation games however the words selected were less difficult. Additionally, regular reading time was replaced with story hour where the teacher read and the readings were dramatized, often with the use of costumes. The effect of the pronunciation game was the same as with group1, the effect of the reading hour and dramatizations was student engagement and request for reading additional materials, by the end of the school year reading time was successfully reimplemented and students willingly engaged in silent reading.

Group 3 was once again comprised of grade three students. These students were amassed of foreign students, high mobility students, and students, “. . clearly from 
second rate institutions." With this group she tried out the learning to read by reading theory. Teachers modified stories loved by the other groups by writing it on the blackboard and developed by story-telling and sense-content methods. Once it was apparent they had awakened the student's interest they moved on to phonic and word drills and continued monitoring progress. This approach resulted in reading at grade level, however pronunciation was still lacking in some.

Group4 was comprised of grade four students all of whom seemed to have an acute phonic sense. Phonic drills were abandoned early in the year for these students. They excelled in all of their studies. The author indicates these students probably would have done well using any method.

The author concludes that phonic drills have real value but are not necessary for every child. Furthermore, phonic drills should be adapted to meet the needs of the student. She goes on to indicate word pronunciation drills were helpful and that oral \& silent reading should be carefully supervised. The two big takeaways were student engagement and coming to the realization that one program should not be used for all students. While it may not have been the intention of this educator to support an interactive approach her conceptualization of the nature of individual differences in reading is illustrative of the manner in which theories progress. In 1980 Stanovich came to a similar conclusion when proposing an interactive model coupled with a compensatory component. 
As was the case with studies of both the bottom-up and top-down approaches, proponents of the interactive approach conducted studies comparing teaching methods or programs as the means in which to quantify the efficacy of the theory. In 2005 Linda Crowe conducted a study that compared two methods to remediate comprehension. The first was decoding based feedback, a linear approach that would support the premise that reading is hierarchical in nature. The other method was meaning based feedback, an interactive approach that encourages the student to access background knowledge while simultaneously attending to more distinct elements. Crowe indicates this method uses multiple levels of information and in so the reader expands their awareness of the purpose and utility of reading.

The sample for this study was small consisting of eight students, recommended for remediation in grades three through five. Pre tests were administered to establish a baseline for improvement. Subsequent tests were administered at five week intervals once the program commenced. Students participating in the meaning based feedback program exhibited significantly greater gains than the decoding based feedback group. Additionally, the meaning based group was able to recall significantly greater story details as opposed to the decoding based group.

Much of the research to date has been comparative in nature. When the focus was on specific skills within the domain it was limited to phonics or phonemic awareness as measures of decoding. Additionally, past studies have included relatively small samples 
sizes $(\mathrm{N}<100)$ and were often non-restrictive relating to age and/or grade associated with early literacy. The present study examines the 10 constructs in Figure 4 which measure decoding, and determines their ability to predict reading ability. The study includes students from kindergarten through second grade, and the sample size is in excess of 500 students.

The questions this study addresses are; 1) does decoding sufficiently predict the reading ability of students in kindergarten, first and second grades, 2) what is the nature of the relationships among skills assessing decoding, 3) what is the relationship between these skills and decoding, 4) what is the relationship between these skills and comprehension, and finally 5) is comprehension mediated by decoding?

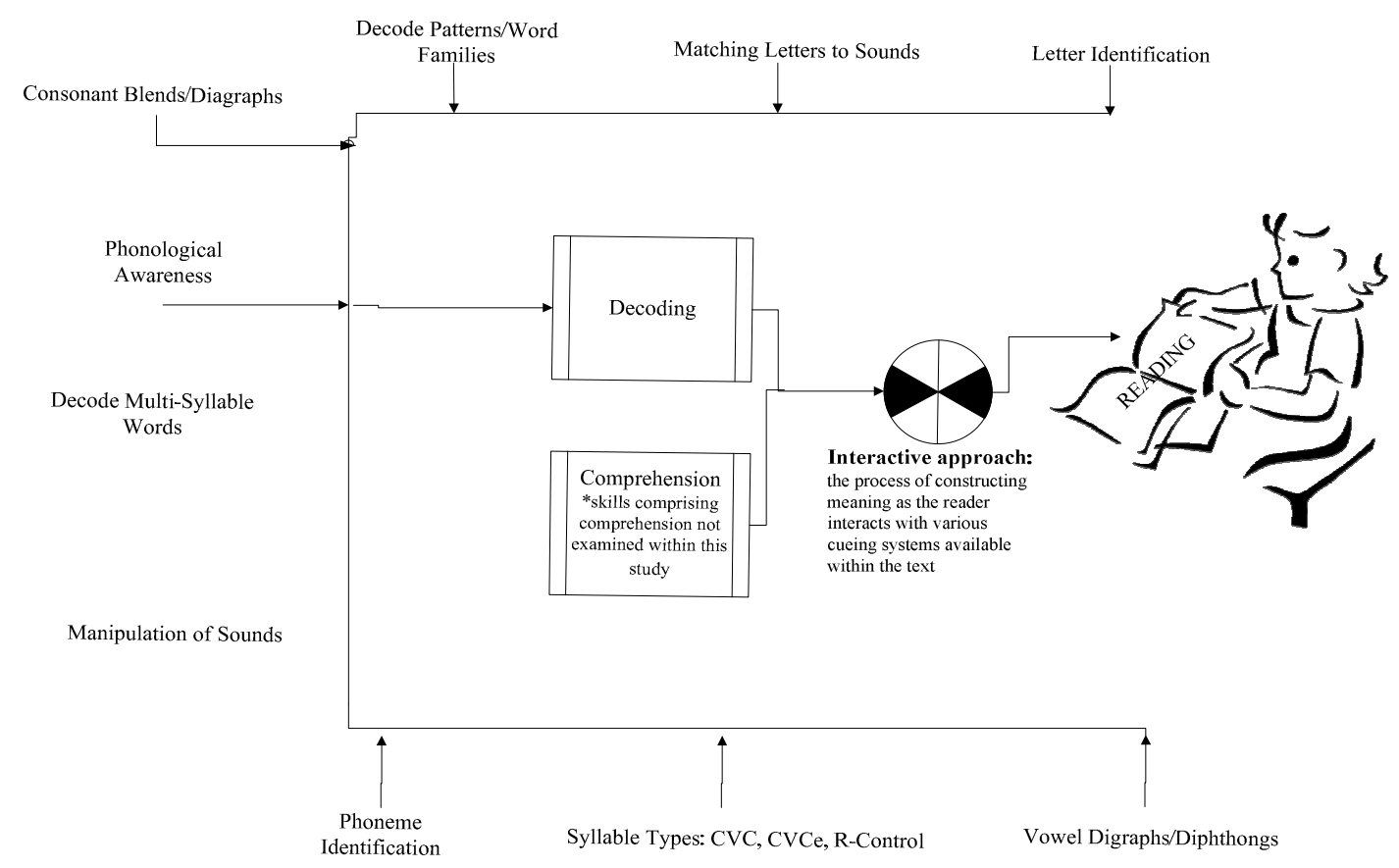

Figure 4 - Does Decoding Predict Reading? 


\section{Chapter 3 - Method}

This chapter provides a description of the statistical models employed to answer the aforementioned research questions. It briefly describes the study participants and provides great detail about the manner in which the domain of reading is assessed. The chapter concludes with the order in which the analysis was carried out as well as modifications that were deemed necessary during initial regression analysis.

\subsection{Model}

Students are assigned an overall reading score based on the combined scores of the two segments. Segment 1 assesses the decoding aspect of reading through the goals of phonological awareness, phonics, and concepts of print. Segment 2 assesses the comprehension aspect of reading through the vocabulary, comprehension, and writing goals.

The analysis methodology employs standard multiple regression with a mediation model. In order to ensure balanced comparisons for mediation, all of the coefficients for each of the 10 discrete decoding skills will be utilized within the regression equation regardless of significance. 
An example regression equation is shown in Equation 1,

$$
Y=a+b x_{1}+b x_{2}+b x_{3}+b x_{4}+b x_{5}+b x_{6}+b x_{7}+b x_{8}+b x_{9}+b x_{10}
$$

where $\mathrm{Y}$ is the dependent variable being predicted, $\mathrm{x}_{\mathrm{i}}$ is the $\mathrm{i}_{\text {th }}$ independent variable, and a is the $\mathrm{Y}$-intercept value.

Mediation occurs when the relationship between the independent variable (IV) and a dependent variable (DV) is explained by the inclusion of a third variable. The directional affect is not directly from the IV to the DV as indicated by 'c' in figure 2 below. Rather, the IV relationship to the DV is affected by the mediator variable (MV) as indicated by ' $a$ '. Furthermore, partial mediation is when the path from the IV to the DV is reduced but is still different from zero and full mediation is when is when the IV no longer affects the DV after the MV has been controlled for.

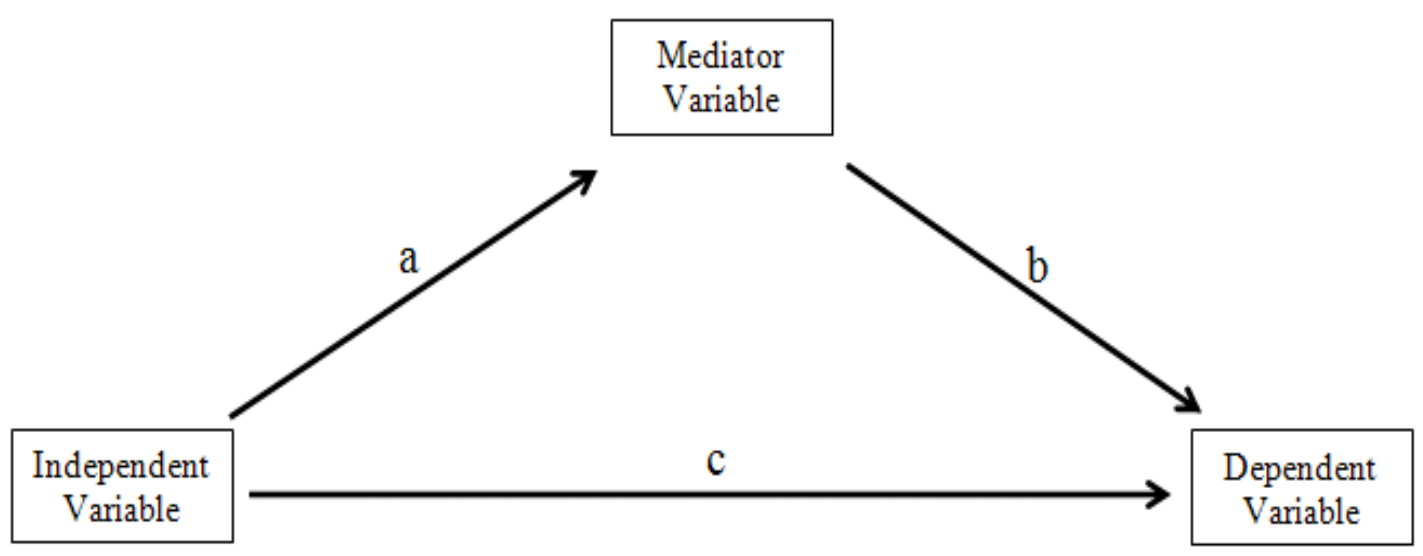

Figure 5 - Mediation 
The model for analysis will proceed as follows using the Baron Kenny approach (1986):

STEP 1 - Show that the initial variable is correlated with the outcome. This step establishes that there is an effect that may be mediated. That is, it establishes the strength of the "c" relationship in the Figure 5 model before mediation. Do this by regressing the segment 2 score on the 10 discrete decoding skills (see Figure 6). This process results in a regression equation and the variance $\left(R^{2}\right)$ in the segment 2 score accounted for by the combination of the 10 discrete decoding skills. It represents the "c" relationship in Figure 5.

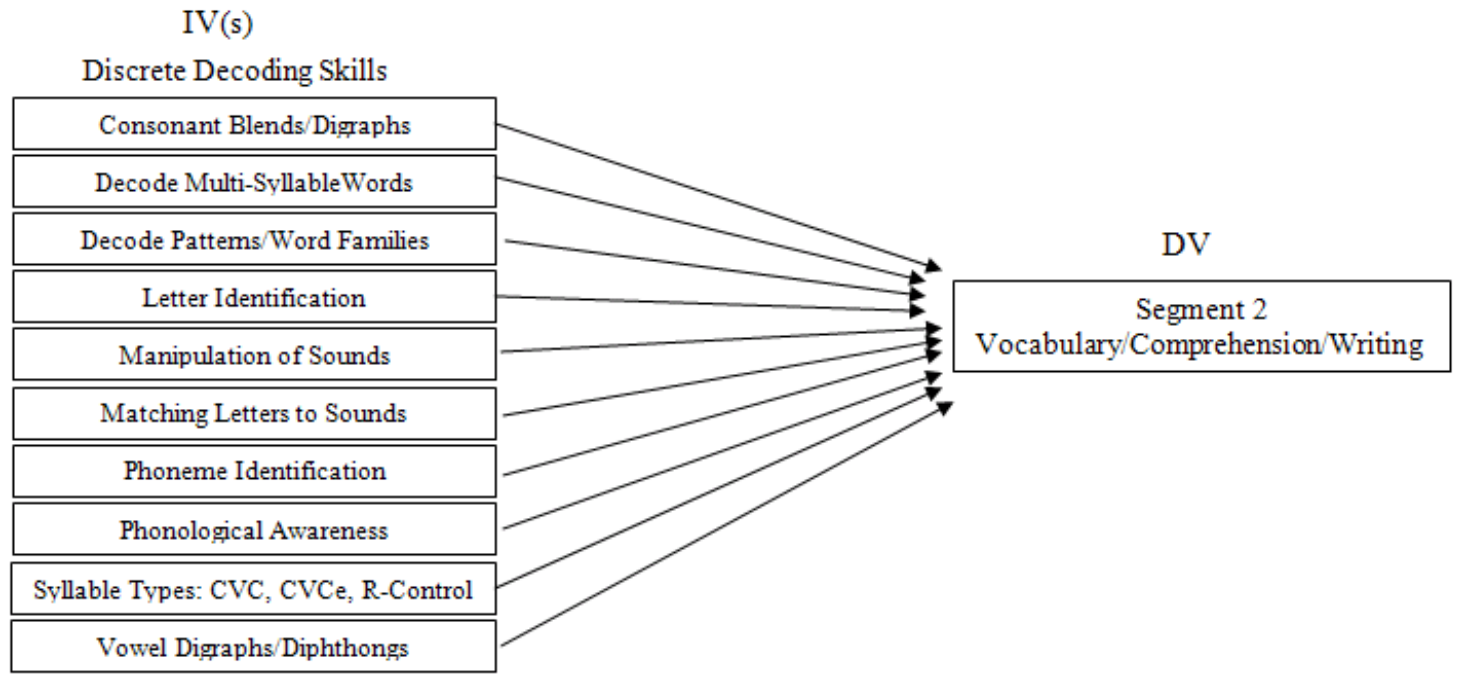

Figure 6 - Regressing Segment 2 on 10 Discrete Decoding Skills 
STEP 2 - Show that the independent variable is correlated with the mediator. This shown by regressing the segment 1 score on the 10 discrete decoding skills (see Figure 7). This process results in the regression equation and computes the variance in the segment 1 score accounted for by the combination of the 10 discrete decoding skills $\left(\mathrm{R}^{2}\right)$. It establishes the "a" relationship represented in Figure 5.

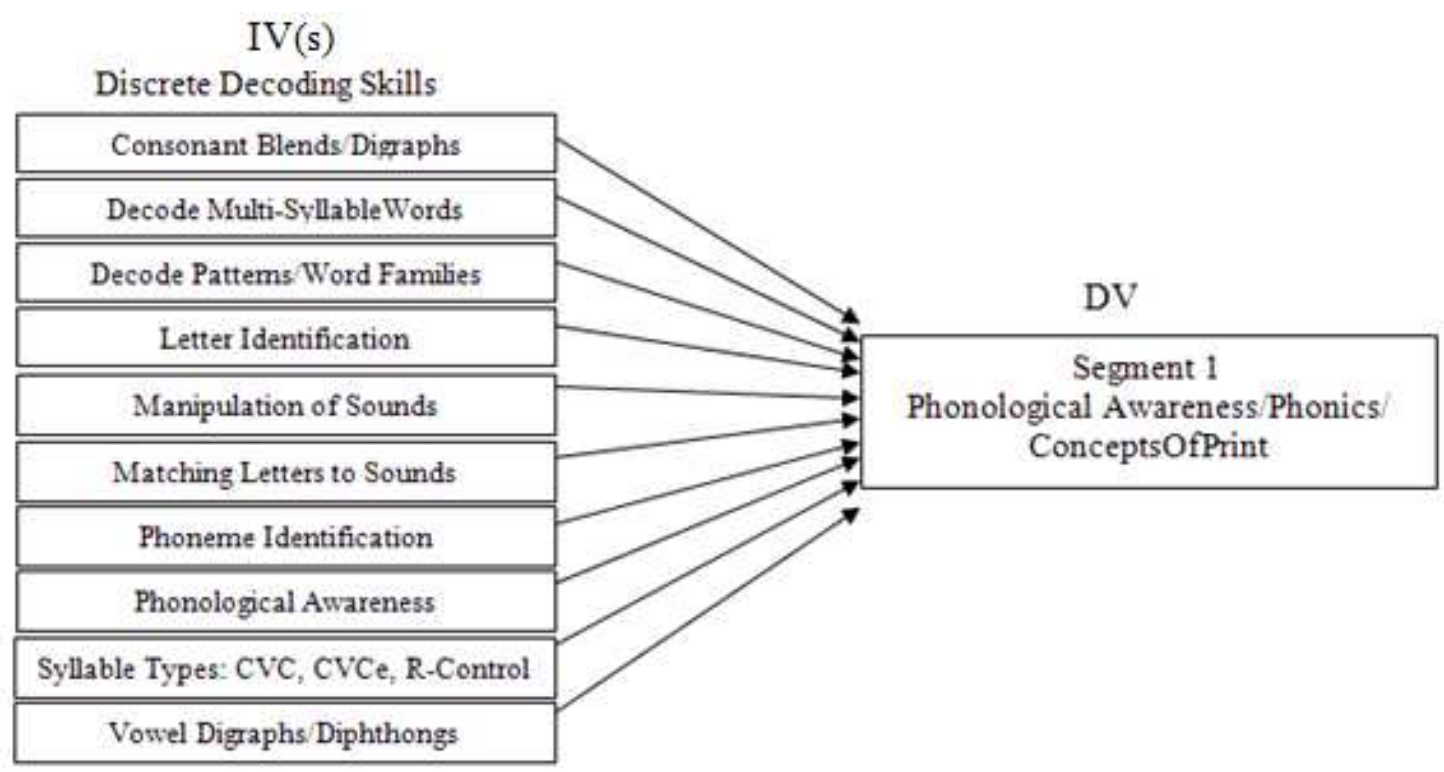

Figure 7 - Regressing Segment 1 on 10 Discrete Decoding Skills

STEP 3 - Show the mediator affects the outcome variable. Do this by regressing the segment 2 score on the segment 1 score (see Figure 8 ). This process results in the regression equation and computes the variance in the segment 2 score accounted for by the segment 1 score $\left(\mathrm{R}^{2}\right)$. It establishes the " $\mathrm{b}$ " relationship represented in Figure 5. 


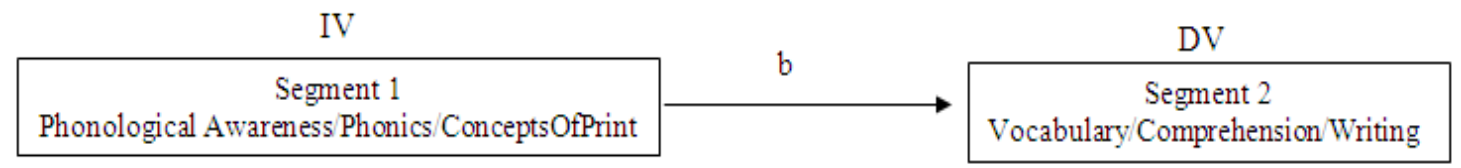

Figure 8 - Regressing Segment 2 on Segment 1

STEP 4 - To establish that the MV completely mediates the IV - DV relationship, the effect of IV on DV controlling for MV should be zero (see Figure 9). If it is not zero but is reduced from its previous value, partial mediation can be claimed. It establishes the "a + b" relationship represented in Figure 5.

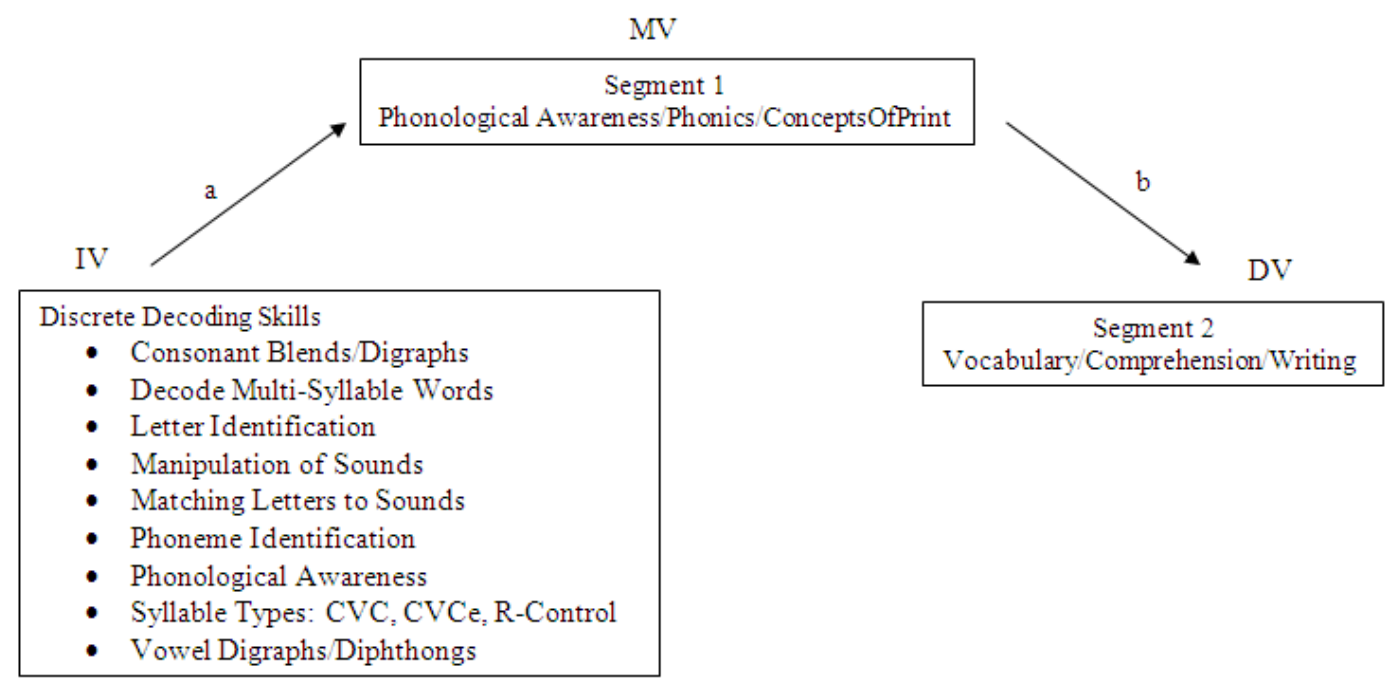

Figure 9 - Segment 1 Mediating the Effect of the Decoding Skills on Segment 2 


\subsection{Participants}

This study utilizes test event results from kindergarten through second grade students who have completed a series of 10 skills tests for reading that assess some aspect of decoding as described within the following section. Additionally, these students will have taken a reading assessment that assess both decoding and comprehension.

\subsection{Instrument}

The children's behaviors will be measured by Northwest Evaluation Association's (NWEA) MAP for Primary Grades Skills Checklist and Survey with Goals Tests. There are 10 skills checklist tests and 2 survey with goals tests. Administration of these computerized tests requires use of headphones and a mouse, a keyboard is not used. Headphones are necessary as all of the items are accompanied by audio given the nature of the construct in conjunction with the age and grade level of the students being assessed. Use of the mouse requires only single, rather than double, click.

\subsubsection{Skills Checklist Tests}

\subsubsection{Item Types}

The skills checklist tests are diagnostic in nature designed to sample instructionally specific content areas as they pertain to decoding. Each of the skills 
checklist tests are fixed form assessments that include one or more familiarization items administered at the start of the test. Familiarization items afford students the opportunity to become familiar with specific item style(s) used throughout the tests without penalty to the student's score. Utilization of these non-scored items provides proctors with additional opportunity to adjust the volume on the computer if necessary without the possible consequence of disengaging the student from the task being measured. There are three item styles that may be employed, hot spots, sticky click, and click and pop. The hot spot item style results in circling the answer option once the student clicks on it by selecting the left mouse button. The sticky click style has the effect of the answer option selected by the student visually sticking to the end of the mouse pointer displayed on the test. The student must then click on the response area to place the answer criteria. This item style differs from the traditional drag and drop method of many computer programs as the student may let up on the mouse button once the answer option is selected and the option will remain on the mouse pointer until the student elects to place the answer option using another mouse click. The click and pop item style has the effect of the answer option popping into the response area after the student clicks on the option. Familiarization items are not scored therefore there is no penalty to the student's score as the student becomes familiar with the manner in which it is necessary to navigate the test. The student is then presented with the scored items randomly selected across the subskills assessed within the skills test. Items are scored dichotomously. The final item in each of the tests acts as a reward for the student completing the test (e.g. a little barking 
dog, wagging its tail with good job below it). The rewards item, like the familiarization items, is not scored. These tests are not timed. Students are encouraged to take their time, do their best, and if they are uncertain they should make their best guess.

\subsubsection{Variables}

The results are reported at the end of the test with both a percent correct and the ratio from which the percent is derived (NWEA 2008). These raw scores are the independent variables used in the model.

\subsubsection{Test Characteristics}

The specific skills checklist tests are Consonant Blends/Digraphs, Decode MultiSyllable Words, Decode Patterns/Word Families, Letter Identification, Manipulation of Sounds, Matching Letters to Sounds, Phoneme Identification, Phonological Awareness, Syllable Types: CVC, CVCe, R-Control, and Vowel Digraphs/Diphthongs.

The Consonant Blends/Digraphs test consists of 47 randomly selected dichotomously scored items across four skills. The skills assessed within this test are initial blends (25 items), final blends (12 items), initial digraphs (5 items), and final digraphs (5 items). The length of the test is 49 items including 1 familiarization and 1 rewards item.

The Decode Multi-Syllable Words test consists of 30 randomly selected dichotomously scored items across five sub-skills nested within two skills. The skills assessed within this test are affixes, assessed across three sub-skills, inflectional endings 
(5 items), prefixes (5 items), suffixes (5 items), and $\mathrm{C}+\mathrm{le}$, assessed across two subskills, open/C + le (5 items) and closed/C + le (10 items). The length of the test is 34 items including 3 familiarization items and 1 rewards item.

The Decode Patterns/Word Families test consists of 18 randomly selected dichotomously scored items across a single skill, word families. The length of the test is 20 items including 1 familiarization and 1 rewards item.

The Letter Identification test consists of 52 randomly selected dichotomously scored items across 2 sub-skills, upper case (26 items), and lower case (26 items) nested within the single skill of letter identification. The length of the test is 54 items including 1 familiarization and 1 rewards item.

The Manipulation of Sounds test consists of 35 randomly selected dichotomously scored items across 3 skills, blending of sounds (10 items), substitution of sounds consisting of 3 sub-skills, beginning sounds ( 5 items), middle sounds (5 items), and ending sounds (5 items), and deletion of sounds (10 items). The length of the test is 38 items including 2 familiarization items and 1 rewards item.

The Matching Letters to Sounds test consists of 31 randomly selected dichotomously scored items across 2 skills, consonant sounds (21 items), and vowel sounds (10 items). The length of the test is 34 items including 2 familiarization items and 1 rewards item. 
The Phoneme Identification test consists of 44 randomly selected dichotomously scored items across 3 skills, initial consonant sounds (19 items), final consonant sounds (15 items), and middle vowel sounds (10 items). The length of the test is 47 items including 2 familiarization items and 1 rewards item.

The Phonological Awareness test consists of 35 randomly selected dichotomously scored items across 3 skills, rhyming (10 items), counting syllables, consisting of 3 subskills, one- syllable words ( 5 items), two-syllable words (5 items), and three-syllable words (5 items), and blending syllables (10 items). The length of the test is 38 items including 2 familiarization items and 1 rewards item.

The Syllable Types: CVC, CVCe, R-Control test consists of 14 randomly selected dichotomously scored items across 3 skills, CVC (5 items), CVCe (4 items), and Rcontrolled (5 items). The length of the test is 16 items including 1 familiarization and 1 rewards item.

The Vowel Digraphs/Diphthongs test consists of 21 randomly selected dichotomously scored items across 2 skills, digraphs (11 items), and diphthongs (10 items). The length of the test is 24 items including 2 familiarization items and 1 rewards item. 


\subsubsection{Survey with Goals Tests}

The survey with goals tests used to assess student ability in reading are divided into two segments to allow young children to finish them without fatigue or distraction.

Segment 1 of the primary grades reading assessment, PRI-READ-Survey w/Goals (PhonAware, Phonic, ConPrnt), is a 35 item test assessing 3 primary reading goals; phonological awareness, phonics, and concepts of print. The resulting segment score is one of the variables used in this analysis. This segment assesses decoding ability through:

- phonemic awareness

$\circ$ the ability to manipulate phonemes in spoken syllables and words - phonics

$\circ$ the study of the relationship between letters and the sounds they represent

- concepts of print

$\circ$ how to hold the book the right way

$\circ$ differentiating between print and pictures

$\circ$ turning pages from left to right

o being able to tell the front of the book from the back

$\circ$ identifying the manner in which lines of text are read (left to right and top to bottom)

o differentiating words from letters

o differentiating between upper and lower case

o identifying punctuation marks in texts

As is the case with the skills checklist tests, both familiarization items and a good job item are presented to the student. The first four items in the test are familiarization items. This test uses all three familiarization items as described in the skills checklist tests as well as a familiarization item in a modified multiple-choice format. Instead of a student selecting either an alpha or numerically labeled answer option the answer option 
is not labeled and the student may left mouse click anywhere on an answer option in order to select it. After the familiarization items have been administered the next 10 items are administered in phase 1 adaptively and selected by identifying highly informative items at each momentary achievement estimate and then randomly selecting an item from that pool (NWEA 2008). The student then sees 6 field test items, these are not scored, followed by another 8 items administered in phase 2 adaptively and selected by identifying highly informative items at each momentary achievement estimate and then randomly selecting an item from that pool (NWEA 2008). The final phase administers 6 items adaptively and selects by identifying highly informative items at each momentary achievement estimate and then randomly selects an item from that pool (NWEA 2008). The test concludes with the administration of a rewards item.

Segment 2 of the primary grades reading assessment, PRI-READ-Survey w/Goals (Vocab, Comprehen, Writing) is a 35 item test assessing 3 primary reading goals; vocabulary and word structure, comprehension, and writing. As was the case with the segment 1 score the resulting segment 2 score is one of the variables used in this analysis. It is administered in the same manner as segment one of the primary grades reading assessment instead using pools of items assessing ability in comprehension and writing through:

- vocabulary and word structure

○ sight words

- content vocabulary

○ context clues 

○ synonyms
$\circ$ antonyms
○ homonyms
o homographs

- comprehension

○ evaluative comprehension

- the ability to understand fact, opinion, bias, assumptions, and elements of persuasion

- can evaluate the validity and quality of written materials

- can compare works, evaluate conclusions, and apply what is learned to real life experiences

$\circ$ interpretive comprehension

- the ability to make reasonable predictions before, during, and after reading

- can draw inferences necessary for understanding

- can recognize and connect cause and effect relationships

- can summarize and synthesize information from a variety of written materials

- literal comprehension

- the ability to recall, identify, classify, sequence details and facts

- interpret directions

- identify stated main ideas from a variety of written materials

- writing

- writing process

- conventions of language

- language structure

- phrase, sentence and paragraph structure

- grammatical patterns

Each segment produces three sub-scores and one overall segment score. Eight items typically support each sub-score, with a range between six and ten items. If students are given both segments within a 28-day window, the two tests are "combined" as if they had taken one test. This results in a more reliable overall score, but does not change any of the sub-scores. Only students taking both segments of the reading survey 
with goals assessment will be included in this study. The combined score resulting from the six sub-scores (three from each segment administered) represents an overall reading score and is also used as a variable in this analysis. These tests use computerized adaptive item selection and scoring algorithms with a basis in item response theory. Scores on these tests are based on the $\mathrm{RIT}^{2}$ scale in reading.

\subsection{Design and Procedure}

In order to conduct the necessary analysis data were gathered from NWEA's Growth Research Database. This database contains test event as well as student data specific to the skills checklists and survey with goals test as described in the previous section.

Analysis began by regressing the Combined MPG Reading score on the scores of the 10 skills checklist tests. I then regressed the score of Segment1 (PhonAware, Phonic, ConPrnt) on the scores of the 10 skills checklist tests. I did the same on the Segment 2(Vocab, Comprehen, Writing) score.

2 An equal interval measure that is one tenth of a logit added to 200. A unit that is derived from test data by applying the Poisson probability theorem. Rasch units, is a name coined by curriculum and evaluation researchers to avoid confusion with other measures (Ingebo 1997, p. 143). 
The findings during the initial regression analysis indicated moderate to high correlations among variables. As such hierarchical regression analysis was conducted to determine if the addition of each independent variable explained incremental variance in the combined Reading Survey with Goals RIT score above and beyond the variance explained by the previous independent variable(s) entered into the regression. The same was done for each segment score.

Analysis concluded by considering the predictability and/or relationship between comprehension and decoding segment scores of the survey with goals assessment and the 10 skills checklists tests using mediation.

The results of the analysis in conjunction with the current theory of reading model the dynamics of reading ability. Figure 10 indicates what the nature of the relationships between the skills assessed by the 10 skills checklist tests and decoding and comprehension may look like. Should the analysis indicate that decoding is not sufficient to predict reading ability in kindergarten, first, and second grade students, the model will provide extensive detail as to the manner in which decoding contributes to overall reading ability. 


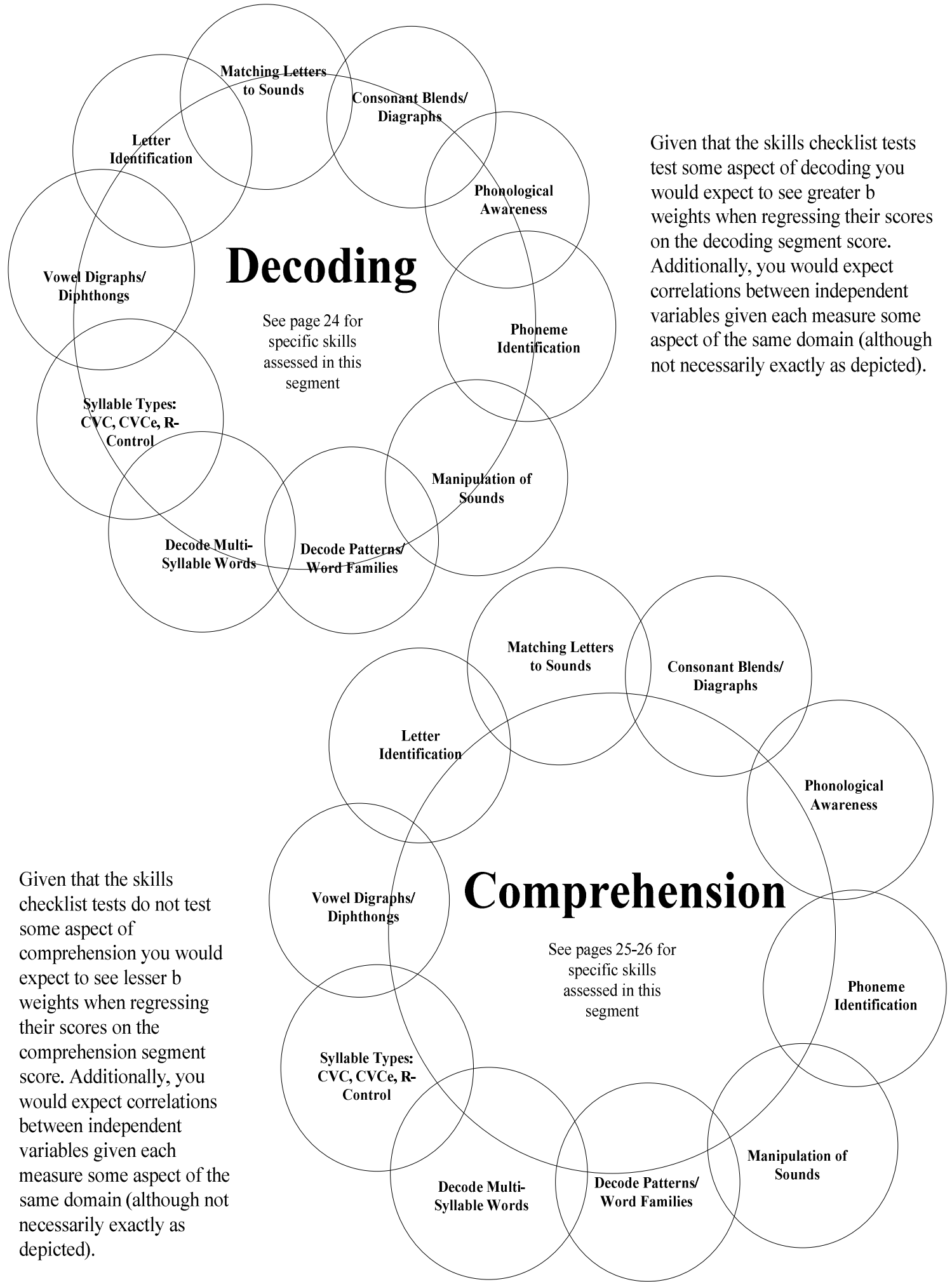

Figure 10 - Regressing the 10 skills checklist tests on the separate segments (decoding \& comprehension) 
This type of systems modeling allows illustration indicating whether or not the stance that reading is not constrained by hierarchical skills, as is posited by the interactive approach is in fact supported by the data.

Finally, the model provides a framework from which subsequent research may extend to include the interactive process between the student and the cueing systems (graphophonic, semantic, and syntactic) available within the text. 
Findings and Results

\section{Chapter 4 - Findings and Results}

This chapter begins by describing the data. It describes the transition of the data from initial collection to final use, and how doing so was necessary to preserve the integrity of the study. Next the results of standard regression on the Combined MPG Reading Survey with Goals RIT score and summary are presented. Regression on each of the segment scores (Segment 1 Reading Score (PhonAware, Phonic, ConPrnt) and Segment 2 Reading Score (Vocab, Comprehen, Writing)) follows. Subsequently hierarchical regression on each of the three aforementioned scores was employed and findings were presented. The chapter closes with the results of mediation using segment 1 as the mediating variable and segment 2 as the dependent variable in the first analysis and segment 2 as the mediating variable with segment 1 as the dependent variable in the second analysis.

\subsection{Description of Data}

Critical review of the original data set composed of 1,106 student records revealed differences in grades across assessments within individual records. To minimize the effect of additional opportunity to learn that is likely to occur for individual students as they progress from one grade to the next records for which student grade was inconsistent were omitted. Doing so reduced the data set from 1,106 to 541 student records (see Table 1). 
Findings and Results

\begin{tabular}{|l|l|l|l|}
\hline \multicolumn{1}{|c|}{ Grade } & \multicolumn{1}{|c|}{$\begin{array}{c}\text { Student Count for } \\
1106 \text { data set }\end{array}$} & \multicolumn{2}{c|}{$\begin{array}{c}\text { Student Count for } \\
541 \text { data set }\end{array}$} \\
\hline $\mathrm{K}$ & 51 & 49 \\
\hline 1 & 543 & 211 \\
\hline 2 & 512 & 281 \\
\hline
\end{tabular}

Table 1 - Data Set Configuration

Removal of the student records for which the grades were inconsistent was important prior to the regression analysis. Doing so reduced biasing the results by artificially inflating individual skill abilities attributable to the opportunity for additional learning and subsequently minimizing the variability in combined scores attributed to the skills.

Conventional standards (Tabachnick and Fidell 2007) indicate a minimum sample size is necessary to satisfy the assumption of ratio of cases to independent variables used within the regression analysis. The data set used in this analysis meet those minimum requirements as measured by the formula below where $\mathrm{N}$ is the number of records and $\mathrm{m}$ is the number of independent variables included.

$$
\begin{aligned}
& N \geq 50+8(\mathrm{~m}) \\
& N \geq 50+8(10) \\
& N \geq 130
\end{aligned}
$$


Findings and Results

\begin{tabular}{|l|l|l|l|l|l|l|l|l|}
\hline $\begin{array}{l}\text { Type of } \\
\text { Variable }\end{array}$ & Variable Long Name & $\begin{array}{l}\text { Variable } \\
\text { Short } \\
\text { Name }\end{array}$ & $\begin{array}{l}\text { Mean } \\
\text { Score }\end{array}$ & $\begin{array}{l}\text { Std. } \\
\text { Dev. }\end{array}$ & N & $\begin{array}{l}\text { Min. } \\
\text { Score }\end{array}$ & $\begin{array}{l}\text { Max } \\
\text { Score }\end{array}$ & $\begin{array}{l}\text { Total } \\
\text { Possible }\end{array}$ \\
\hline DV & $\begin{array}{l}\text { Combined MPG Reading } \\
\text { Survey with Goals Score }\end{array}$ & RIT Score & 177.58 & 16.839 & 541 & 128 & 219 & $*$ \\
\hline IV & Consonant Blends/Digraphs & CBD & 34.79 & 11.362 & 541 & 8 & 47 & 47 \\
\hline IV & $\begin{array}{l}\text { Decode: Pattems/Word } \\
\text { Families }\end{array}$ & DPWF & 13.67 & 4.110 & 541 & 2 & 18 & 18 \\
\hline IV & $\begin{array}{l}\text { Decode: Multi-Syllable } \\
\text { Words }\end{array}$ & DMSW & 15.94 & 8.298 & 541 & 1 & 30 & 30 \\
\hline IV & Letter Identification & LI & 50.70 & 5.299 & 541 & 9 & 52 & 52 \\
\hline IV & Manipulation of Sounds & MoS & 23.90 & 7.875 & 541 & 5 & 35 & 35 \\
\hline IV & Matching Letters to Sounds & MLtS & 28.85 & 4.343 & 541 & 3 & 31 & 31 \\
\hline IV & Phoneme Identification & PI & 28.36 & 11.013 & 541 & 5 & 44 & 44 \\
\hline IV & Phonological Awareness & PA & 23.46 & 6.938 & 541 & 4 & 35 & 35 \\
\hline IV & $\begin{array}{l}\text { Syllable Types: CVC, } \\
\text { CVCe, R-Control }\end{array}$ & ST & 10.59 & 3.404 & 541 & 0 & 14 & 14 \\
\hline IV & $\begin{array}{l}\text { Vowel } \\
\text { Diagraphs } \text { Diphthongs }\end{array}$ & VDD & 14.96 & 5.824 & 541 & 1 & 21 & 21 \\
\hline
\end{tabular}

Table 2 - Variable Descriptives

DV = Dependent variable

IV = Independent variable

* = not applicable as this is a scale score with a range from $100-350$

Tables three through five below provide the reader with the means to interpret the reading scores.

\begin{tabular}{|l|l|l|l|}
\hline Grade & \multicolumn{1}{|c|}{$1^{\text {st }}$} & \multicolumn{1}{|c|}{$50^{\text {th }}$} & \multicolumn{1}{|c|}{$9^{\text {th }}$} \\
Percentile & Percentile & Percentile \\
\hline K & 138 & 146 & 170 \\
\hline 1 & 140 & 160 & 185 \\
\hline 2 & 156 & 179 & 210 \\
\hline
\end{tabular}

Table 3 - Reading RIT Scores Beginning of School Year

\begin{tabular}{|l|l|l|l|}
\hline Grade & $\begin{array}{c}1^{\text {st }} \\
\text { Percentile }\end{array}$ & \multicolumn{1}{c|}{$\begin{array}{c}50^{\text {th }} \\
\text { Percentile }\end{array}$} & $\begin{array}{c}9^{\text {th }} \\
\text { Percentile }\end{array}$ \\
\hline K & 138 & 151 & 177 \\
\hline 1 & 143 & 167 & 189 \\
\hline 2 & 159 & 186 & 215 \\
\hline
\end{tabular}

Table 4 - Reading RIT Scores Middle of School Year

\begin{tabular}{|l|l|l|l|}
\hline Grade & \multicolumn{1}{|c|}{$1^{\text {st }}$} & \multicolumn{1}{c|}{$50^{\text {th }}$} & $\begin{array}{c}99^{\text {th }} \\
\text { Percentile }\end{array}$ \\
Percentile & Percentile \\
\hline 1 & 138 & 155 & 183 \\
\hline 2 & 143 & 173 & 192 \\
\hline
\end{tabular}

Table 5 - Reading RIT Scores, End of School Year 
Findings and Results

\subsection{Regressing the Combined MPG Reading Score on the 10 Skills Checklist Scores}

Visual inspection of the scatterplots between the dependent variable and each of the independent variables indicate regression is appropriate. All appear to be linear although a few seem to have a weak relationship to the dependent variable. See figures 11 through 18 for bivariate scatterplots between the dependent variable, RIT Score, and 8 of the independent variables.

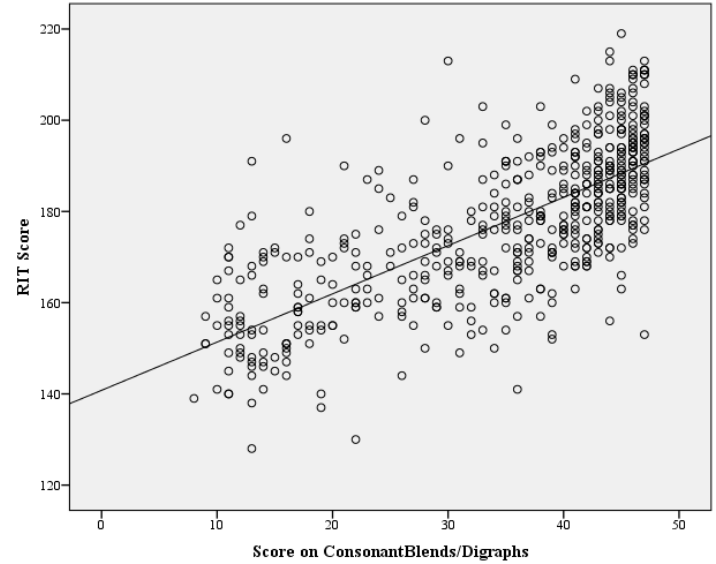

Figure 11 - Scatterplot (RIT Score; CBD)

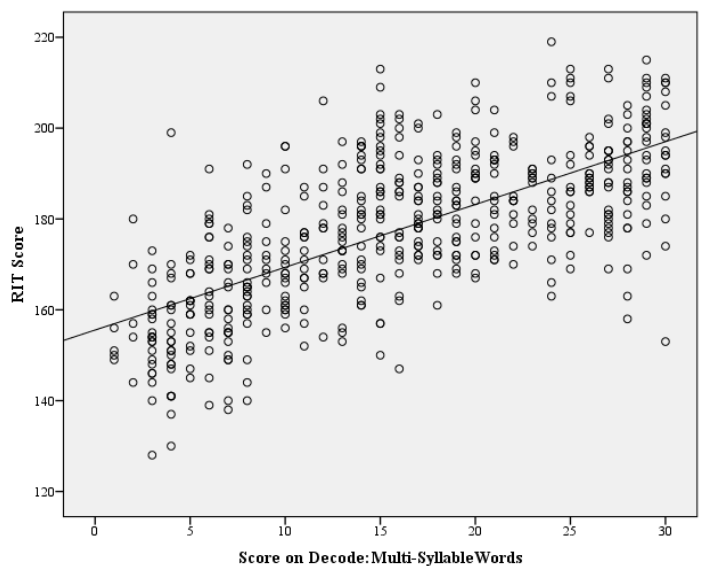

Figure 13 - Scatterplot (RIT Score; DMSW)

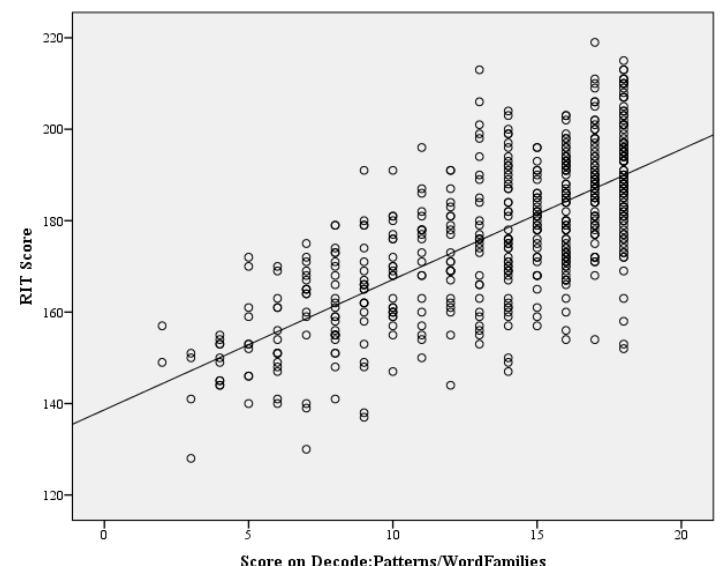

Figure 12 - Scatterplot (RIT Score; DPWF)

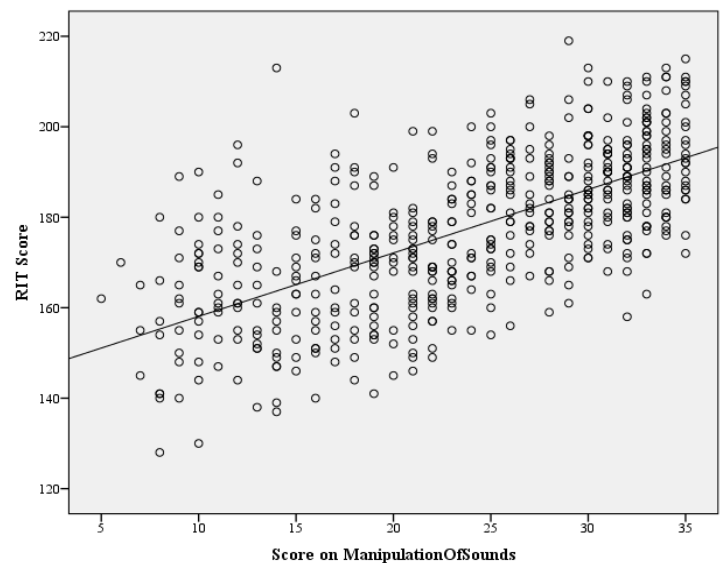

Figure 14 - Scatterplot (RIT Score; MoS) 


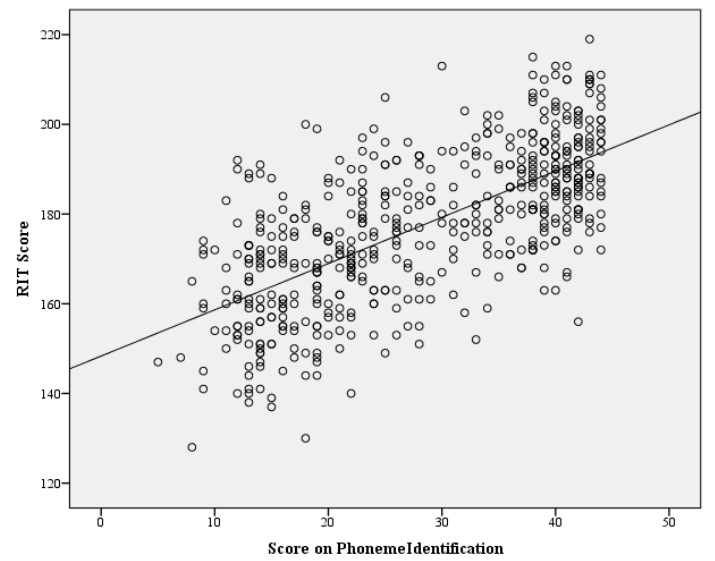

Figure 15 - Scatterplot (RIT Score; PI)

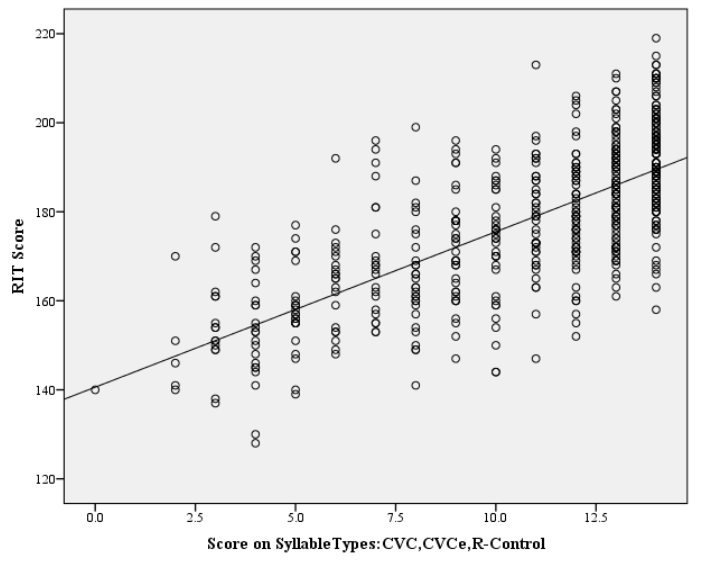

Figure 17 - Scatterplot (RIT Score; ST)

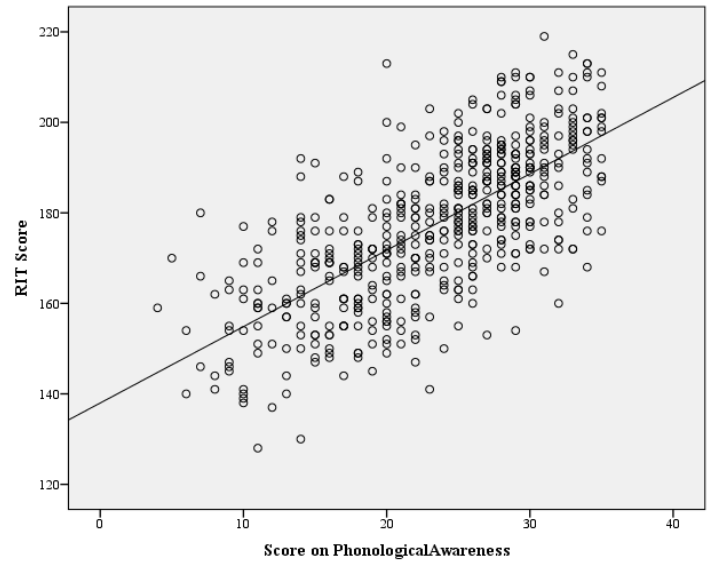

Figure 16 - Scatterplot (RIT Score; PA)

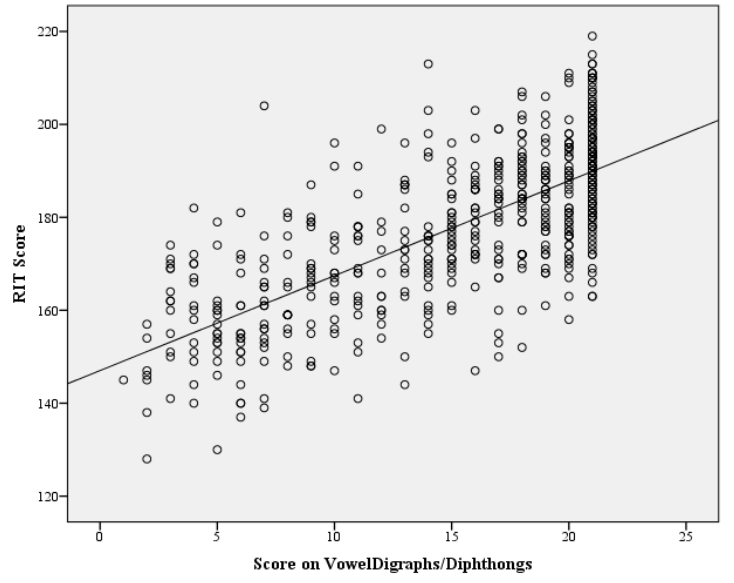

Figure 18 - Scatterplot (RIT Score; VDD)

Eight of the ten independent variables (Consonant Blends/Digraphs, Decode:

Patterns/Word Families, Decode: Multi-Syllable Words, Manipulation of Sounds, Phoneme Identification, Phonological Awareness, Syllable Types: CVC, CVCe, RControl, Vowel Digraphs/Diphthongs) exhibited a positive, linear relationship with the 
Findings and Results

score for the combined MPG Reading Survey with Goals test with no major outliers. The variability, $\mathrm{R}^{2}$, accounted for in the MPG Reading Survey with Goals test score by each of these variables when considered individually is indicated in Table 6. The interpretation of the $\mathrm{R}^{2}$ value pertains to the variance accounted for in the RIT Scores when only the individual independent variable is considered (e.g. $50.9 \%$ of the variance in the Combined Reading Survey with Goals Score may be attributed to the score on the Consonant Blends/Digraphs skills checklist test).

\begin{tabular}{|l|l|}
\hline Independent Variable & $\mathbf{R}^{2}$ \\
\hline Consonant Blends/Digraphs & 0.509 \\
\hline Decode: Patterns/Word Families & 0.483 \\
\hline Decode: Multi-Syllable Words & 0.464 \\
\hline Manipulation of Sounds & 0.430 \\
\hline Phoneme Identification & 0.455 \\
\hline Phonological Awareness & 0.484 \\
\hline Syllable Types: CVC, CVCe, R-Control & 0.498 \\
\hline Vowel Digraphs/Diphthongs & 0.498 \\
\hline
\end{tabular}

Table 6 - Variability Accounted for in RIT Score

The scores on Letter Identification and Matching Letters to Sounds exhibited a weak, positive linear relationship with the score for the combined MPG Reading Survey with Goals test. The assumption of homoscedasticity appears to be violated as well (see figures 19 and 20 respectively). 


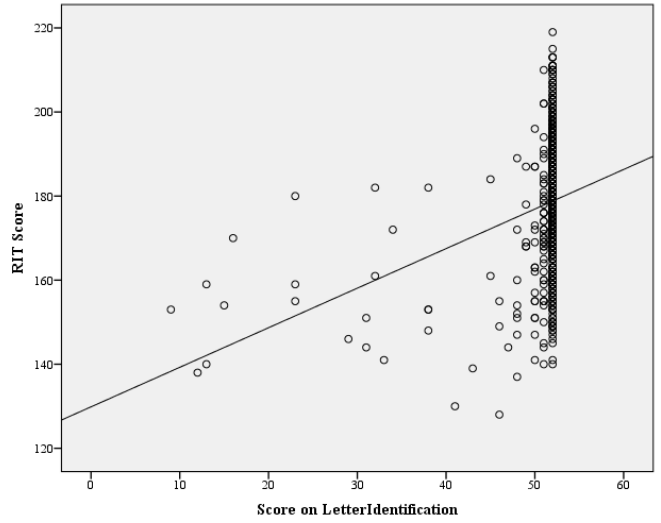

Figure 19 - Scatterplot (RIT Score; LI)

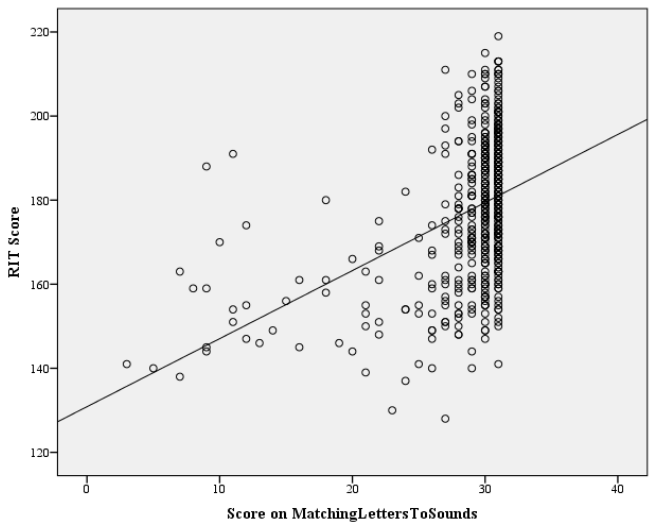

Figure 20 - Scatterplot (RIT Score; MLtS)

The variance accounted for in the MPG Reading Survey with Goals test score by each variable when considered individually was, $R^{2}=.088$ and $R^{2}=0.17$ respectively. The assumption of homoscedasticity appears to have been violated for both as well. This made sense since the mean score on these tests across all 3 grades was near perfect score as indicated in Table 7.

\begin{tabular}{|l|l|l|l|}
\hline Independent Variable & Mean Score & Median & Total Possible \\
\hline Letter Identification & 50.70 & 52 & 52 \\
\hline Matching Letters to Sounds & 28.85 & 30 & 31 \\
\hline
\end{tabular}

Table 7 - Descriptive Statistics for LI and MLtS

The mean and median for each of the two aforementioned skills were close.

Therefore transforming the variables did not satisfy the assumption of homoscedasticity. See Figures 21 and 22 as evidence. Given the negative skew of the original variables, the variables were reflected $($ in SPSS syntax ReflectedVariable $=(($ OldVariableMax +1$)-$ 
OldVariable) and a transformation applied as would be applicable for severe positive skew (in SPSS syntax TransformedVariable $=1 /$ ReflectedVariable).

Furthermore, the resulting plots are easily misinterpreted given the scale of the chart. Initial visual inspection of these plots may lead one to believe the scores are far more disparate than the data indicate. In Figure 21 the data points indicated at 1.00 along the horizontal axis represent a perfect score of 52 on Letter Identification, while the data points between 0.40 and 0.60 represent a near perfect score of 51 .

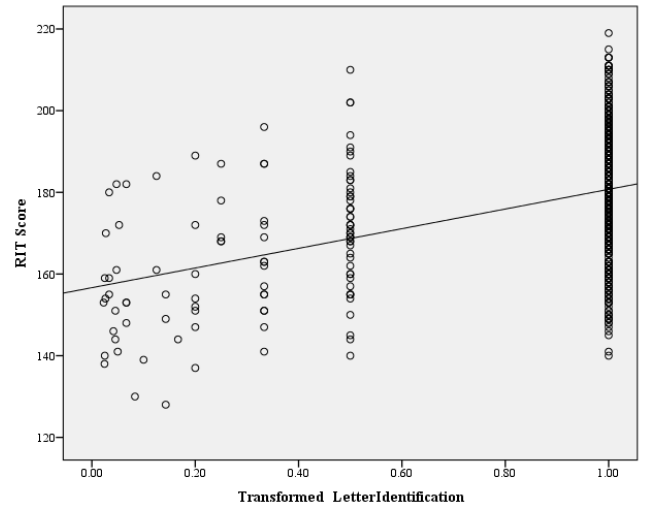

Figure 21 - Scatterplot after Transformation (LI)

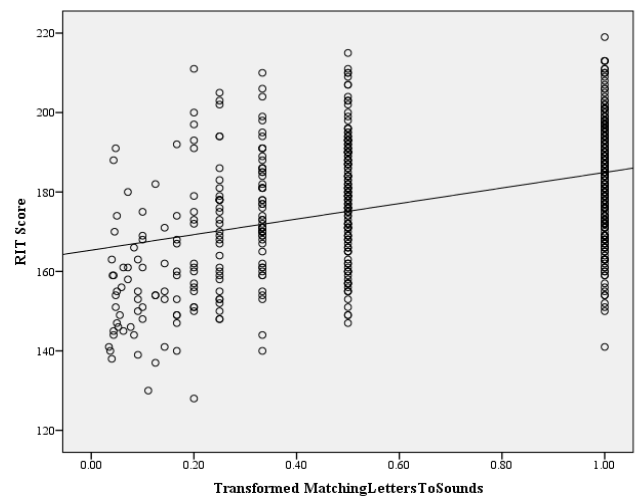

Figure 22 - Scatterplot after Transformation (MLtS)

These variables were recoded, using 1 for proficient (based on the mean) and 0 as not proficient in order to conduct post hoc analysis to further examine the distribution of combined RIT scores between each group (proficient and not proficient) of students. Table 8 illustrates the cut points. Figures 23 through 26 further illustrate the distribution of reading scores among proficient and non-proficient students in each of the skills 
Findings and Results

(Letter Identification and Matching Letters to Sounds). Additionally, the extent to which each grade contributes to the designated groups is provided.

\begin{tabular}{|l|c|c|c|}
\hline Independent Variable & Mean Score & Proficient (1) & Not Proficient (0) \\
\hline Letter Identification & 50.70 & $\geq 50$ & $<50$ \\
\hline Matching Letters to Sounds & 28.85 & $\geq 28$ & $<28$ \\
\hline
\end{tabular}

Table 8 - Recoded Variables

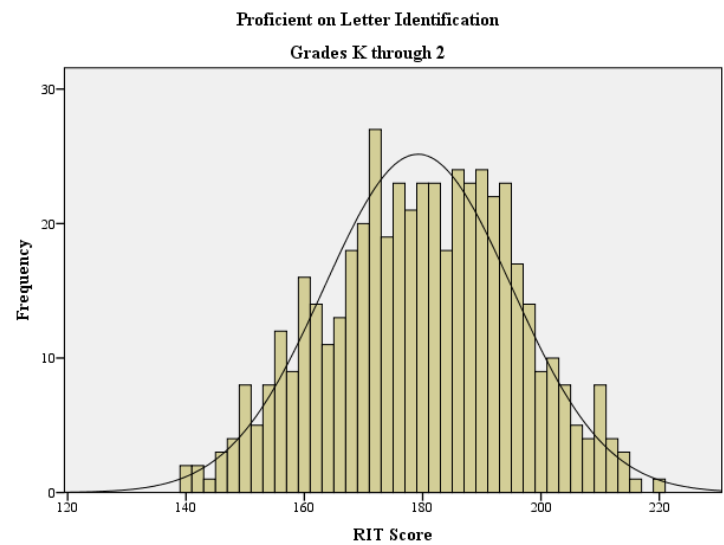

Figure 23 - Proficient (LI)

Proficient $\geq 50 / 52$

$\mathrm{N}=500$ (Approx $92 \%$ of sample)

$\mathrm{N} /$ Grade $=\mathrm{K}=35 ; 1^{\text {st }}=194 ; 2^{\text {nd }}=271$

Min RIT Score $=140$

Max RIT Score $=219$

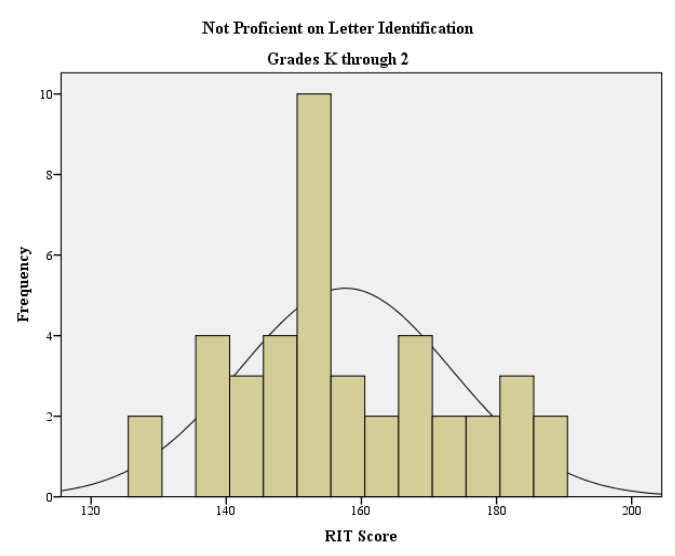

Figure 24 - Not Proficient (LI)

Not Proficient $<50 / 52$

$\mathrm{N}=41$ (Approx $8 \%$ of sample)

$\mathrm{N} /$ Grade $=\mathrm{K}=14 ; 1^{\text {st }}=17 ; 2^{\text {nd }}=10$

Min RIT Score $=128$

Max RIT Score $=189$ 
Findings and Results

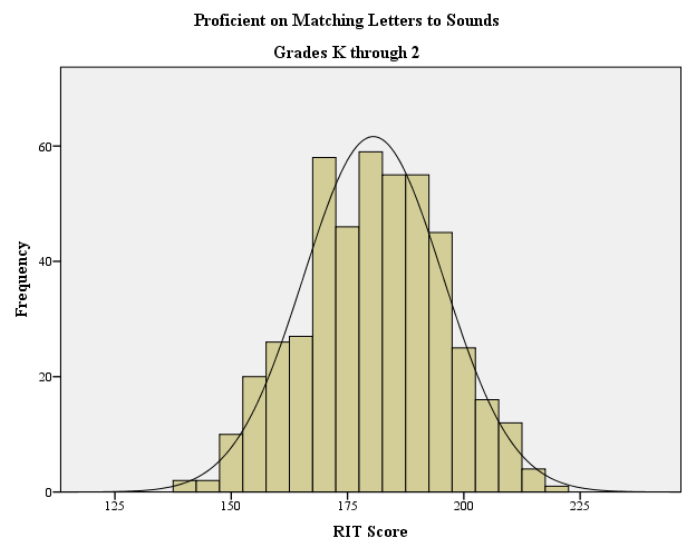

Figure 25 - Proficient (MLtS)

Proficient $\geq 28 / 32$

$\mathrm{N}=463$ (Approx $86 \%$ of sample)

$\mathrm{N} / \mathrm{Grade}=\mathrm{K}=23 ; 1^{\text {st }}=183 ; 2^{\text {nd }}=257$

Min RIT Score $=140$

Max RIT Score $=219$

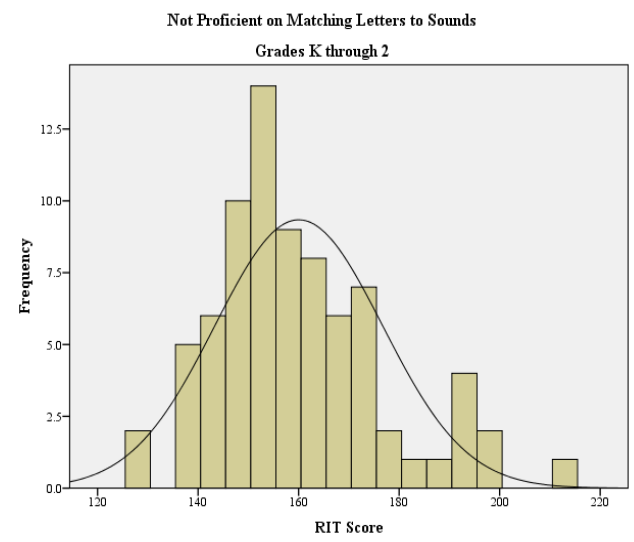

Figure 26 - Not Proficient (MLtS)

Not Proficient $<28 / 32$

$\mathrm{N}=78$ (Approx 14\% of sample)

$\mathrm{N} /$ Grade $=\mathrm{K}=26 ; 1^{\text {st }}=28 ; 2^{\text {nd }}=24$

Min RIT Score $=128$

Max RIT Score $=211$

Of the 41 students not proficient on Letter Identification 25 of them were also not proficient on Matching Letters to Sounds. The distribution of student's scores meeting this criteria are presented in Figure 27 below.

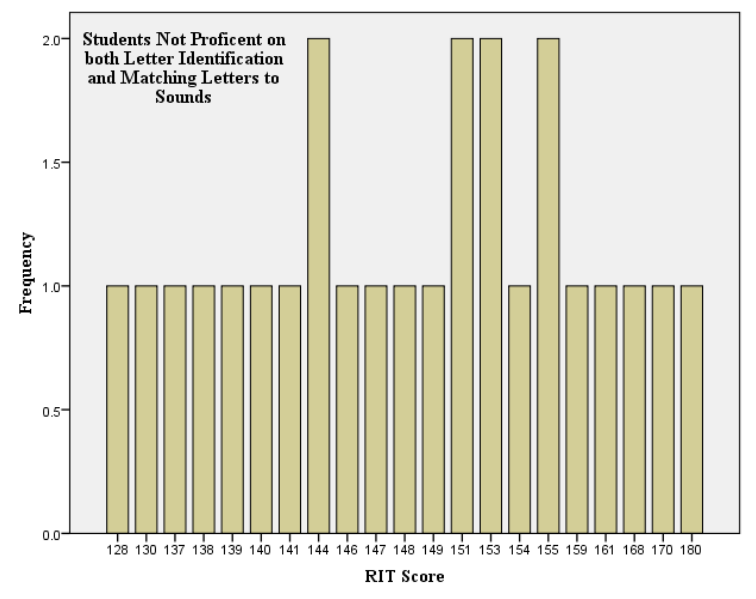

Figure 27 - Not Proficient on both LI and MLtS
Not Proficient on Letter Identification $<50 / 52$

Not Proficient on Matching Letters to $<28 / 32$ Sounds

$\mathrm{N}=25$ (Approx 5\% of sample)

N/Grade $-K=12 ; 1^{\text {st }}=9 ; 2^{\text {nd }}=4$

Min RIT Score $=128$

Max RIT Score $=180$ 
Findings and Results

With the exception of scores on Letter Identification and Matching Letters to Sounds each of the independent variables (Consonant Blends/Digraphs, Decode: Patterns/Word Families, Decode: Multi-Syllable Words, Manipulation of Sounds, Phoneme Identification, Phonological Awareness, Syllable Types: CVC, CVCe, RControl, and Vowel Digraphs/Diphthongs), when plotted with the dependent variable (Combined MPG Reading Survey with Goals score), supports the assumption of homoscedasticity.

Multiple regression indicates little effect on residuals as a result of the two heteroscedastic independent variables (Letter Identification and Matching Letters to Sounds), see Figures 28 through 30 below.

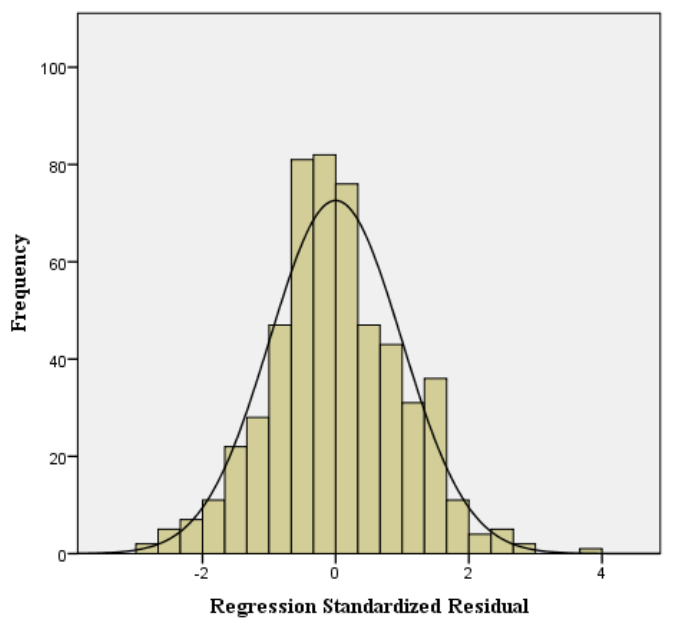

Figure 28 - Regression Residuals for RIT Score

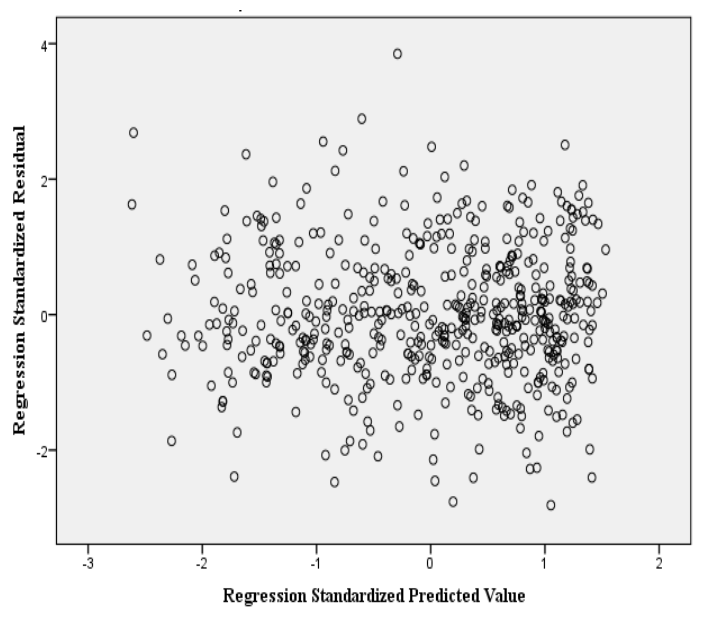

Figure 29 - Scatterplot of Residuals 
Findings and Results

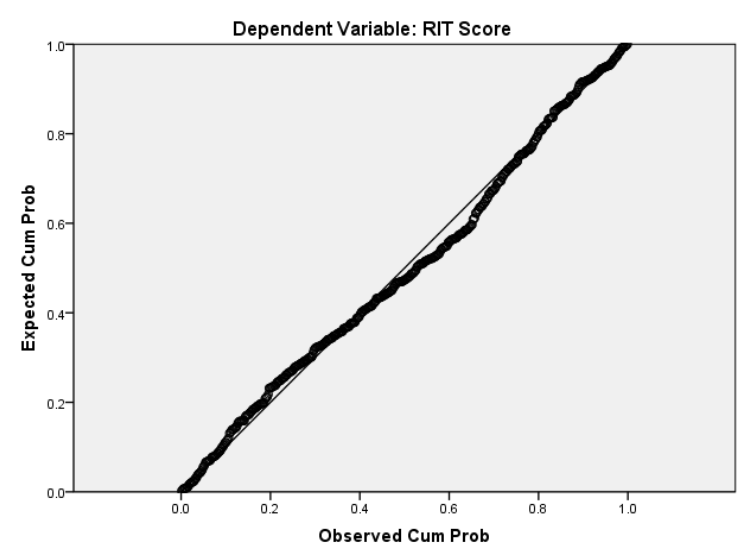

Figure 30 - P-Plot of Regression Residuals

The resulting correlations indicated multicollinearity could be an issue.

Multicollinearity occurs when the correlation between variables $\geq .90$. The correlations varied from a low of .248 to a high of .880 . The lower correlations were between two distinct groups of independent variables. The first group consists of Letter Identification and Matching Letters to Sounds, and the second group is comprised of the remaining eight independent variables in conjunction with the dependent variable. The moderate to high correlations were among the remaining eight independent variables (Consonant Blends/Digraphs, Decode: Patterns/Word Families, Decode: Multi-Syllable Words, Manipulation of Sounds, Phoneme Identification, Phonological Awareness, Syllable Types: CVC, CVCe, R-Control, and Vowel Digraphs/Diphthongs) and the dependent variable (Combined MPG Reading Survey with Goals score) ranging from .617 to .880. Correlations between Letter Identification and Matching Letters to Sounds were moderate at .579 (see Table 9). 


\begin{tabular}{|l|c|c|c|c|c|c|c|c|c|c|c|}
\hline & RIT & CBD & DPWF & DMSW & LI & MoS & MLtS & PI & PA & ST & VDD \\
\hline RIT & - & & & & & & & & & & \\
\hline CBD & .714 & - & & & & & & & & & \\
\hline DPWF & .695 & .830 & - & & & & & & & & \\
\hline DMSW & $.681^{*}$ & .766 & .770 & - & & & & & & & \\
\hline LI & .296 & .313 & .290 & .248 & - & & & & & & \\
\hline MoS & .656 & .721 & .648 & .660 & .318 & - & & & & & \\
\hline MLtS & .418 & .500 & .442 & .370 & .579 & .432 & - & & & & \\
\hline PI & $.674^{*}$ & .721 & .649 & .639 & .265 & .756 & .429 & - & & & \\
\hline PA & $.695^{*}$ & .714 & .663 & .652 & .315 & .721 & .450 & .726 & - & & \\
\hline ST & .706 & .797 & .810 & .761 & .330 & .654 & .474 & .657 & .689 & - & \\
\hline VDD & $.706^{*}$ & .790 & .816 & .764 & .268 & .617 & .410 & .633 & .648 & .880 & - \\
\hline
\end{tabular}

Table 9 - Correlations Between Variables

* significant B weights

The regression equation using the $\mathrm{B}$ weights and constant from the coefficients table is as follows:

$Y^{\prime}=128.375+.095 x_{1}+.334 x_{2}+.223 x_{3}+.096 x_{4}+.150 x_{5}+.037 x_{6}+.221 x_{7}+.489 x_{8}+$ $.236 x_{9}+.536 x_{10}$

$\mathrm{Y}^{\prime}$ is the predicted value of the Combined MPG Reading Survey with Goals Test score. The constant value 128.375 represents the mean Combined MPG Reading Survey with Goals Test score if all of the scores on the 10 skills checklists tests were held constant at 0 . The values in Table 10 associated with variables $\mathrm{x}_{1}$ through $\mathrm{x}_{10}$ represent the change in the Combined MPG Reading Survey with Goals Test score for every one unit of change in the independent variable enumerated holding all other independent variables constant. 
Findings and Results

\begin{tabular}{|c|c|c|c|c|c|}
\hline \multirow[t]{2}{*}{ Model } & \multicolumn{2}{|c|}{$\begin{array}{c}\text { Unstandardized } \\
\text { Coefficients }\end{array}$} & Standardized Coefficients & \multirow[t]{2}{*}{$\mathrm{t}$} & \multirow[t]{2}{*}{ Sig. } \\
\hline & $\mathrm{B}$ & Std. Err & Beta & & \\
\hline 1 Constant & 128.375 & 4.333 & & 29.625 & .000 \\
\hline $\mathrm{x}_{1} \quad \mathrm{CBD}$ & .095 & .086 & .064 & 1.114 & .266 \\
\hline $\mathrm{x}_{2} \quad \mathrm{DPWF}$ & .334 & .226 & .081 & 1.476 & .141 \\
\hline $\mathrm{x}_{3} \quad \mathrm{DMSW}$ & .223 & .096 & .110 & 2.333 & $.020 *$ \\
\hline $\mathrm{X}_{4} \quad \mathrm{LI}$ & .096 & .103 & .030 & .932 & .352 \\
\hline $\mathrm{x}_{5} \mathrm{MoS}$ & .150 & .098 & .070 & 1.538 & .125 \\
\hline $\mathrm{x}_{6} \quad \mathrm{MLtS}$ & .037 & .138 & .010 & .267 & .790 \\
\hline $\begin{array}{ll}\mathrm{X}_{7} & \mathrm{PI} \\
\end{array}$ & .221 & .069 & .145 & 3.183 & $.002 *$ \\
\hline $\mathrm{X}_{8} \quad \mathrm{PA}$ & .489 & .107 & .201 & 4.553 & $.000 *$ \\
\hline $\mathrm{x}_{9} \quad \mathrm{ST}$ & .236 & .307 & .048 & .767 & .444 \\
\hline $\mathrm{x}_{10} \mathrm{VDD}$ & .536 & .176 & .186 & 3.048 & $.002 *$ \\
\hline
\end{tabular}

Table 10 - Coefficients Table

* indicates significant

Decode Multi-Syllable Words, Phoneme Identification, Phonological Awareness, and Vowel Digraphs/Diphthongs are all significant predictors in the Combined MPG Reading Test. However, Consonant Blends/Digraphs, Decode: Patterns/Word Families, Letter Identification, Manipulation of Sounds, Matching Letters to Sounds, and Syllable Types: CVC, CVCe, R-Control are not significant predictors in the Combined MPG Reading Test.

\begin{tabular}{|l|l|l|l|l|}
\hline Model & R & R Square & Adjusted R Square & Std. Error of the Estimate \\
\hline 1 & .799 & .639 & .632 & 10.218 \\
\hline
\end{tabular}

Table 11 - Model Summary Table

From the model summary table we found that $\mathrm{R}^{2}=.639$. This indicated that approximately $64 \%$ of the variance in RIT scores was accounted for by scores on all 10 of the skills checklist tests. Additionally, the analysis of variance (ANOVA) table 
indicated a significant relationship between the 10 skills checklist tests (as a group) and the RIT score on the combined MPG Reading Test, $\mathrm{F}(10,530)=93.65, \mathrm{p}<.001, \mathrm{R}^{2}=.64$.

\begin{tabular}{|l|r|r|r|c|c|}
\hline Model & Sum of Squares & df & $\begin{array}{c}\text { Mean } \\
\text { Square }\end{array}$ & F & Sig. \\
\hline 1 Regression & 97777.827 & 10 & 9777.783 & 93.650 & .000 \\
$\begin{array}{l}\text { Residual } \\
\text { Total }\end{array}$ & 55335.925 & 530 & 104.407 & & \\
\hline
\end{tabular}

Table 12 - ANOVA

Furthermore, the coefficient of variation (CV) for the regression is:

$$
C V=\frac{10.218}{128.375}=.080
$$

The coefficient of variation represents the ratio of the standard error of the estimate to the mean (in this case the constant from the coefficients table represents the mean overall MPG Reading Survey with Goals Test score if all of the scores on the 10 skills checklists tests were held constant at 0 ). When the $\mathrm{CV}<.10$, as it is when the Combined MPG Reading Survey with Goals Test score is regressed on the 10 skill checklists test scores, it is an indication that the model may be useful for prediction purposes. 
Findings and Results

\subsubsection{Summary of Regression Results}

Multiple regression analysis was used to evaluate how the scores on 10 distinct skills tests (Consonant Blends/Digraphs, Decode: Patterns/Word Families, Decode:

Multi-Syllable Words, Letter Identification, Manipulation of Sounds, Matching Letters to Sounds, Phoneme Identification, Phonological Awareness, Syllable Types: CVC, CVCe, R-Control, and Vowel Digraphs/Diphthongs) assessing various aspects of decoding relate jointly and uniquely to scores on a reading assessment administered to a group of students in kindergarten through second grade. As a group Consonant Blends/Digraphs, Decode: Patterns/Word Families, Decode: Multi-Syllable Words, Letter Identification, Manipulation of Sounds, Matching Letters to Sounds, Phoneme Identification, Phonological Awareness, Syllable Types: CVC, CVCe, R-Control, and Vowel Digraphs/Diphthongs explained significant variance in the reading assessment scores, $F(10,530)=93.65, p<.001, R^{2}=.64$., indicating $64 \%$ of the variance in reading scores can be accounted for by the combination of the 10 decoding skills.

In Table 13, indices are presented to indicate the relative strength of the individual predictors when controlling for all other predictor variables. All partial correlations between decoding skills and reading were positive, and four of the skills were statistically significant $(\mathrm{p}<.05)$. 
Findings and Results

\begin{tabular}{|l|c|c|c|}
\hline Predictor Variable & $\mathrm{B}$ & $\mathrm{t}$ & $\mathrm{p}$ \\
\hline CBD & .095 & 1.11 & .266 \\
\hline DPWF & .334 & 1.48 & .141 \\
\hline DMSW & .223 & 2.33 & $.020^{*}$ \\
\hline LI & .096 & 0.93 & .352 \\
\hline MoS & .150 & 1.54 & .125 \\
\hline MLtS & .037 & 0.27 & .790 \\
\hline PI & .221 & 3.18 & $.002^{*}$ \\
\hline PA & .498 & 4.55 & $.000^{*}$ \\
\hline ST & .236 & 0.78 & .444 \\
\hline VDD & .536 & 3.05 & $.002^{*}$ \\
\hline
\end{tabular}

Table 13 - Strength of Predictor Controlling for Other Predictors

* indicates significant

Interpretation for each predictive variable is as follows; controlling for the remaining nine predictive variables the variable of interest (Decode: Multi-Syllable Words in the example that follows) was positively and significantly/not significantly related to the reading assessment score.

Example: Controlling for Consonant Blends/Digraphs, Decode: Patterns/Word Families, Letter Identification, Manipulation of Sounds, Matching Letters to Sounds, Phoneme Identification, Phonological Awareness, Syllable Types: CVC, CVCe, R-Control, and Vowel Digraphs/Diphthongs, scores on Decode: Multi-Syllable Words skills tests were positively and significantly related to the reading assessment scores $(B=.223, t(530)=$ $2.33, p=.020$ ). This means that for every 1 point scored by a student on the skill test, Decode: Multi-Syllable Words, you would expect an increase of .22 RIT points in the student's Combined MPG Reading Survey with Goals Test score. 
Findings and Results

\subsection{Regressing the Segment 1 Reading Score (PhonAware, Phonic, ConPrnt) on the 10 Skills Checklist Scores}

The correlations between the Segment 1 Reading score and the 10 skills checklist tests aligned similarly to the correlations to the Combined MPG Reading Survey with Goals Test score. Letter Identification and Matching Letters to Sounds exhibited weak correlations whereas the remaining eight skills checklist scores indicate moderate correlations. Table 14 provides the correlations between the Segment 1 Reading score, the Combined MPG Reading Survey with Goals Test score, and the change in correlation values when regressing on the segment 1 score rather than the Combined MPG Reading Survey with Goals Test score.

\begin{tabular}{|c|c|c|c|c|c|c|c|c|c|c|}
\hline & CBD & DPWF & DMSW & LI & MoS & MLtS & PI & PA & ST & VDD \\
\hline Segment1 & .656 & .637 & $.644^{*}$ & .296 & .631 & .388 & $.646^{*}$ & $.672 *$ & .655 & .633 \\
\hline RIT Score & .714 & .695 & $.681 *$ & .296 & .656 & .418 & $.674 *$ & $.695^{*}$ & .706 & $.706^{*}$ \\
\hline $\begin{array}{l}\text { Change in } \\
\text { correlation } \\
\text { when } \\
\text { regressed } \\
\text { on Segment } \\
1 \\
\text { (red } \\
\text { indicates a } \\
\text { decrease, } \\
\text { black } \\
\text { indicates no } \\
\text { change) }\end{array}$ & .058 & .058 & .037 & 0 & .025 & .03 & .028 & .023 & .051 & .073 \\
\hline
\end{tabular}

Table 14 - Comparison of Correlations

* significant $B$ weights 
Findings and Results

The regression equation using the B weights and constant from the coefficients table is as follows:

$Y^{\prime}=124.273+.031 x_{1}+.276 x_{2}+.345 x_{3}+.201 x_{4}+.199 x_{5}-.057 x_{6}+.278 x_{7}+.640 x_{8}+$ $.532 x_{9}+.215 x_{10}$

\begin{tabular}{|c|c|c|c|c|c|}
\hline \multirow[t]{2}{*}{ Model } & \multicolumn{2}{|c|}{ Unstandardized Coefficients } & Standardized Coefficients & \multirow[t]{2}{*}{$\mathrm{t}$} & \multirow[t]{2}{*}{ Sig. } \\
\hline & $\mathrm{B}$ & Std. Err & Beta & & \\
\hline 1 Constant & 124.273 & 5.415 & & 22.949 & .000 \\
\hline $\begin{array}{ll}\mathrm{x}_{1} & \mathrm{CBD} \\
\end{array}$ & .031 & .107 & .018 & .287 & .774 \\
\hline $\begin{array}{ll}\mathrm{x}_{2} & \mathrm{DPWF} \\
\end{array}$ & .276 & .283 & .059 & .975 & .330 \\
\hline $\mathrm{x}_{3} \quad$ DMSW & .345 & .120 & .149 & 2.878 & $.004^{*}$ \\
\hline $\begin{array}{ll}\mathrm{x}_{4} & \mathrm{LI} \\
\end{array}$ & .201 & .128 & .055 & 1.564 & .118 \\
\hline $\mathrm{x}_{5} \mathrm{MoS}$ & .199 & .122 & .081 & 1.632 & .103 \\
\hline $\begin{array}{ll}\mathrm{x}_{6} & \mathrm{MLtS} \\
\end{array}$ & -.057 & .173 & -.013 & -.333 & .740 \\
\hline $\begin{array}{ll}\mathrm{x}_{7} & \mathrm{PI} \\
\end{array}$ & .278 & .087 & .159 & 3.205 & $.001^{*}$ \\
\hline $\mathrm{PA}$ & .640 & .134 & .231 & 4.771 & $.000^{*}$ \\
\hline $\begin{array}{ll}\mathrm{X}_{9} & \mathrm{ST} \\
\end{array}$ & .532 & .384 & .094 & 1.385 & .167 \\
\hline $\mathrm{x}_{10} \mathrm{VDD}$ & .215 & .220 & .065 & .977 & .329 \\
\hline
\end{tabular}

\section{Table 15 - Coefficients Table}

* indicates significant

Regressing the Segment 1 score (Phonological Awareness, Phonics, and Concepts of Print) on the skill scores yielded similar results in regards to significance/nonsignificance as with the Combined Reading score with the exception of Vowel Digraphs/Diphthongs. When regressing the Combined RIT score this skill was significant. However, when regressing on the segment 1 score this is no longer the case (now $p=.329$ vs. $p=.002$ ). See Tables 16 and 17 below for $B$ weights, $t$, and significance $(p)$. 
Findings and Results

\begin{tabular}{|c|l|l|l|l|}
\hline $\begin{array}{c}\text { Regressed } \\
\text { On }\end{array}$ & Skill & $B$ & $t$ & $p$ \\
\hline \multirow{4}{*}{$\begin{array}{c}\text { Segment 1 } \\
\text { (PhonAware, } \\
\text { Phonic, }\end{array}$} & CBD & .031 & .287 & .774 \\
\cline { 2 - 5 } & DPWF & .276 & .975 & .330 \\
\cline { 2 - 5 } ConPrnt) & DMSW & .345 & 2.878 & $.004^{*}$ \\
\cline { 2 - 5 } & MoS & .201 & 1.654 & .118 \\
\cline { 2 - 5 } & MLtS & -.057 & -.333 & .740 \\
\cline { 2 - 5 } & PI & .278 & 3.205 & $.001^{*}$ \\
\cline { 2 - 5 } & PA & .640 & 4.771 & $.00 *^{*}$ \\
\cline { 2 - 5 } & ST & .532 & 1.385 & .167 \\
\cline { 2 - 5 } & VDD & .215 & .977 & .329 \\
\hline
\end{tabular}

\begin{tabular}{|c|l|l|l|l|}
\hline $\begin{array}{c}\text { Regressed } \\
\text { On }\end{array}$ & \multicolumn{1}{|c|}{ Skill } & \multicolumn{1}{|c|}{$B$} & \multicolumn{1}{|c|}{$t$} & $p$ \\
\hline \multirow{4}{*}{$\begin{array}{c}\text { Combined } \\
\text { Reading } \\
\text { Assessment }\end{array}$} & CBD & .095 & 1.114 & .266 \\
\cline { 2 - 5 } & DPWF & .334 & 1.476 & .141 \\
\cline { 2 - 5 } & DMSW & .223 & 2.333 & $.020^{*}$ \\
\cline { 2 - 5 } & LI & .096 & .932 & .352 \\
\cline { 2 - 5 } & MoS & .150 & 1.538 & .125 \\
\cline { 2 - 5 } & MLtS & .037 & .267 & .790 \\
\cline { 2 - 5 } & PI & .221 & 3.183 & $.002^{*}$ \\
\cline { 2 - 5 } & PA & .489 & 4.553 & $.000^{*}$ \\
\cline { 2 - 5 } & ST & .236 & .767 & .444 \\
\cline { 2 - 5 } & VDD & .536 & 3.048 & $.002^{*}$ \\
\hline
\end{tabular}

Table 16 - Segment 1

Table 17 - Combined Reading Assessment

The model summary from Table 18 indicated that approximately 57\% of the variance in segment 1 scores is accounted for by scores on all 10 of the skills checklist tests.

\begin{tabular}{|l|l|l|l|l|}
\hline Model & R & R Square & Adjusted R Square & Std. Error of the Estimate \\
\hline 1 & .754 & .568 & .560 & 12.769 \\
\hline
\end{tabular}

Table 18 - Model Summary Table

The ANOVA table indicated a significant relationship between the 10 skills checklist tests (as a group) and the score on the segment 1 test, $\mathrm{F}(10,530)=69.75$, $\mathrm{p}<.000, \mathrm{R}^{2}=.57$.

\begin{tabular}{|l|r|r|r|r|r|}
\hline Model & Sum of Squares & df & $\begin{array}{c}\text { Mean } \\
\text { Square }\end{array}$ & F & Sig. \\
\hline 1 Regression & 113732.024 & 10 & 11373.202 & 69.755 & .000 \\
Residual & 86413.240 & 530 & 163.044 & & \\
Total & 153113.752 & 540 & & & \\
\hline
\end{tabular}

Table 19 - ANOVA 
Findings and Results

The coefficient of variation reveals the model may not be useful for predictive purposes. In contrast to the $\mathrm{CV}$ for the Combined RIT score, the $\mathrm{CV}$ for segment 1 exceeded .10 .

$$
C V=\frac{12.769}{124.273}=.103
$$

\subsection{Regressing the Segment 2 Reading Score (Vocab, Comprehen, Writing) on the 10 Skills Checklist Scores}

The correlations between the Segment 2 Reading score and the 10 skills checklist tests aligned similarly to the correlations to both, the Segment 1 (PhonAware,Phonic,ConPrnt) Test score, and the Combined MPG Reading Survey with Goals Test score. Letter Identification and Matching Letters to Sounds exhibited weak correlations whereas the remaining eight skills checklist scores indicate moderate to high correlations. Table 20 provides the correlations between the Segment 2 Reading score, the Segment 1 Reading score, the Combined MPG Reading Survey with Goals Test score, and the change in correlation values when regressing on the segment 2 score rather than the Combined MPG Reading Survey with Goals Test score. 
Findings and Results

\begin{tabular}{|c|c|c|c|c|c|c|c|c|c|c|}
\hline & CBD & DPWF & DMSW & LI & MoS & MLtS & PI & PA & ST & VDD \\
\hline Segment2 & .704 & .688 & .659 & .260 & .618 & .402 & $.642^{*}$ & $.651^{*}$ & .692 & $.712^{*}$ \\
\hline Segment1 & .656 & .637 & $.644^{*}$ & .296 & .631 & .388 & $.646^{*}$ & $.672^{*}$ & .655 & .633 \\
\hline RIT Score & .714 & .695 & $.681^{*}$ & .296 & .656 & .418 & $.674 *$ & $.695^{*}$ & .706 & $.706^{*}$ \\
\hline $\begin{array}{l}\text { Change in } \\
\text { correlation } \\
\text { when regressed } \\
\text { on Segment } 2 \\
\text { (red indicates a } \\
\text { decrease, } \\
\text { blackindicates } \\
\text { anincrease) }\end{array}$ & .010 & .007 & .022 & .036 & .038 & .016 & .032 & .044 & .014 & .006 \\
\hline
\end{tabular}

Table 20 - Comparison of Correlations

* significant B weights

The regression equation using the B weights and constant from the coefficients

table is as follows:

$Y^{\prime}=133.010+.152 x_{1}+.360 x_{2}+.148 x_{3}-.015 x_{4}+.098 x_{5}+.103 x_{6}+.192 x_{7}+.345 x_{8}+$ $.044 x_{9}+.792 x_{10}$

\begin{tabular}{|c|c|c|c|c|c|}
\hline \multirow[t]{2}{*}{ Model } & \multicolumn{2}{|c|}{$\begin{array}{l}\text { Unstandardized } \\
\text { Coefficients }\end{array}$} & Standardized Coefficients & \multirow[t]{2}{*}{$\mathrm{t}$} & \multirow[t]{2}{*}{ Sig. } \\
\hline & $\mathrm{B}$ & Std. Err & Beta & & \\
\hline 1 Constant & 133.010 & 4.461 & & 29.817 & .000 \\
\hline $\mathrm{x}_{1} \quad \mathrm{CBD}$ & .152 & .088 & .105 & 1.728 & .084 \\
\hline $\mathrm{x}_{2} \quad \mathrm{DPWF}$ & .360 & .233 & .089 & 1.548 & .122 \\
\hline $\mathrm{x}_{3} \quad \mathrm{DMSW}$ & .148 & .099 & .074 & 1.502 & .134 \\
\hline $\mathrm{X}_{4} \quad \mathrm{LI}$ & -.015 & .106 & -.005 & -.145 & .885 \\
\hline $\mathrm{x}_{5} \mathrm{MoS}$ & .098 & .100 & .047 & .977 & .329 \\
\hline $\begin{array}{ll}\mathrm{x}_{6} & \mathrm{MLtS} \\
\end{array}$ & .103 & .142 & .027 & .722 & .471 \\
\hline $\begin{array}{ll}\mathrm{x}_{7} & \mathrm{PI} \\
\end{array}$ & .192 & .071 & .128 & 2.691 & $.007 *$ \\
\hline $\mathrm{x}_{8} \quad \mathrm{PA}$ & .345 & .111 & .145 & 3.123 & $.002 *$ \\
\hline $\begin{array}{ll}\mathrm{X}_{9} & \mathrm{ST} \\
\end{array}$ & .044 & .316 & .009 & .140 & .889 \\
\hline $\mathrm{x}_{10}$ VDD & .792 & .181 & .279 & 4.372 & $.000 *$ \\
\hline
\end{tabular}

Table 21 - Coefficients Table

* indicates significant 
Findings and Results

Regressing the Segment 2 score (Vocab, Comprehen, Writing) on the skill scores yielded similar results in regards to significance/non-significance as with the Combined Reading score with the exception of Decode: Multi-Syllable Words. When regressing the Combined RIT score this skill was significant. However, when regressing on the segment 2 score this is no longer the case (now $p=.134$ vs. $p=.020$ ). See Tables 22 through 24 below for $B$ weights, $t$, and significance $(p)$.

\begin{tabular}{|c|l|l|l|l|}
\hline $\begin{array}{c}\text { Regressed } \\
\text { On }\end{array}$ & Skill & $B$ & $t$ & $p$ \\
\hline \multirow{4}{*}{$\begin{array}{c}\text { Segment } 2 \\
\text { (Vocab, }\end{array}$} & CBD & .152 & 1.728 & .084 \\
\cline { 2 - 5 } & DPWF & .360 & 1.548 & .122 \\
\cline { 2 - 5 } $\begin{array}{l}\text { Comprehen, } \\
\text { Writing) }\end{array}$ & DMSW & .148 & 1.502 & .134 \\
\cline { 2 - 5 } & MoS & -.015 & -.145 & .885 \\
\cline { 2 - 5 } & MLtS & .103 & .972 & .329 \\
\cline { 2 - 5 } & PI & .192 & 2.691 & $.007^{*}$ \\
\cline { 2 - 5 } & PA & .345 & 3.123 & $.002^{*}$ \\
\cline { 2 - 5 } & ST & .044 & .140 & .889 \\
\cline { 2 - 5 } & VDD & .792 & 4.372 & $.000^{*}$ \\
\hline
\end{tabular}

Table 22 - Segment 2

\begin{tabular}{|c|l|l|l|l|}
\hline $\begin{array}{c}\text { Regressed } \\
\text { On }\end{array}$ & Skill & $B$ & $t$ & $p$ \\
\hline \multirow{4}{*}{$\begin{array}{c}\text { Segment 1 } \\
\text { (PhonAware, } \\
\text { Phonic, } \\
\text { ConPmt) }\end{array}$} & CBD & .031 & .287 & .774 \\
\cline { 2 - 5 } & DPWF & .276 & .975 & .330 \\
\cline { 2 - 5 } & DMSW & .345 & 2.878 & $.004^{*}$ \\
\cline { 2 - 5 } & MoS & .201 & 1.654 & .118 \\
\cline { 2 - 5 } & MLtS & -.057 & -.333 & .740 \\
\cline { 2 - 5 } & PI & .278 & 3.205 & $.001^{*}$ \\
\cline { 2 - 5 } & PA & .640 & 4.771 & $.000^{*}$ \\
\cline { 2 - 5 } & ST & .532 & 1.385 & .167 \\
\cline { 2 - 5 } & VDD & .215 & .977 & .329 \\
\hline
\end{tabular}

Table 23 - Segment 1

\begin{tabular}{|c|l|l|l|l|}
\hline $\begin{array}{c}\text { Regressed } \\
\text { On }\end{array}$ & Skill & $B$ & $t$ & $p$ \\
\hline \multirow{4}{*}{$\begin{array}{c}\text { Combined } \\
\text { Reading } \\
\text { Assessment }\end{array}$} & CBD & .095 & 1.114 & .266 \\
\cline { 2 - 5 } & DPWF & .334 & 1.476 & .141 \\
\cline { 2 - 5 } & DMSW & .223 & 2.333 & $.020^{*}$ \\
\cline { 2 - 5 } & LI & .096 & .932 & .352 \\
\cline { 2 - 5 } & MoS & .150 & 1.538 & .125 \\
\cline { 2 - 5 } & MLtS & .037 & .267 & .790 \\
\cline { 2 - 5 } & PI & .221 & 3.183 & $.002^{*}$ \\
\cline { 2 - 5 } & PA & .489 & 4.553 & $.000^{*}$ \\
\cline { 2 - 5 } & ST & .236 & .767 & .444 \\
\cline { 2 - 5 } & VDD & .536 & 3.048 & $.002^{*}$ \\
\hline
\end{tabular}

Table 24 - Combined Reading Assessment 
Findings and Results

The model summary in Table 25 indicated that approximately $57 \%$ of the variance in segment 1 scores is accounted for by scores on all 10 of the skills checklist tests.

\begin{tabular}{|l|l|l|l|l|}
\hline Model & R & R Square & Adjusted R Square & Std. Error of the Estimate \\
\hline 1 & .777 & .604 & .596 & 10.519 \\
\hline
\end{tabular}

Table 25 - Model Summary Table

The ANOVA table indicated a significant relationship between the 10 skills checklist tests (as a group) and the score on the segment 2 test, $\mathrm{F}(10,530)=80.721, \mathrm{p}<$ $.000, \mathrm{R}^{2}=.60$.

\begin{tabular}{|l|r|r|r|c|c|}
\hline Model & Sum of Squares & df & $\begin{array}{c}\text { Mean } \\
\text { Square }\end{array}$ & F & Sig. \\
\hline 1 Regression & 89313.453 & 10 & 8931.345 & 80.721 & .000 \\
Residual & 58641.546 & 530 & 110.664 & & \\
Total & 147954.998 & 540 & & & \\
\hline
\end{tabular}

Table 26 - ANOVA

The coefficient of variation indicated the model may be useful for predictive purposes. Similar to the $\mathrm{CV}$ for the Combined RIT score, the $\mathrm{CV}$ for segment $2<.10$.

$$
C V=\frac{10.519}{133.010}=.079
$$


Findings and Results

\subsection{Hierarchical Regression}

Given the moderate to high correlations among independent variables hierarchical regression was employed. Hierarchical regression determines if the addition of each independent variable explains incremental variance in the combined Reading Survey with Goals RIT score above and beyond the variance explained by the previous independent variable entered into the regression. It will also indicate if the variance in each step contributes significantly to the combined Reading Survey with Goals RIT score. As was done with multiple regression, the segment scores will also be regressed.

\subsubsection{Combined Reading Survey with Goals RIT Score}

Prior regression analysis indicated that only 4 (Decode: Multi-Syllable Words, Phonemic Identification, Phonological Awareness, and Vowel, Digraphs/Diphthongs) of the 10 skills checklist tests accounted statistically significantly for the variance in the Combined Reading score. In conducting hierarchical regression analysis each of these four IVs were entered into the regression first within their own blocks. Additionally, the individual regression analysis on both the segment 1 and segment 2 scores revealed that only two of those independent variables (Phonological Awareness and Phonemic Identification) were significant to both segments. As such these two IVs entered the regression first ordered by significance and correlation to the combined reading score as indicated by their standardized coefficient (Beta). 
Findings and Results

The standardized coefficient (Beta) was used rather than the unstandardized coefficient (B weight) to inform desired order of variable entry. While B weights are useful for constructing the regression equation they are not useful for understanding the relative importance of the predictors. Beta coefficients are more interpretable if the independent and dependent variables are standardized to have a mean of zero and a standard deviation of 1 (Green and Salkind 2008). A greater absolute value of the Beta coefficient indicates greater importance of the variable as a predictor.

The next two IVs (Vowel Digraphs/Diphthongs and Decode: Multi-Syllable Words) followed, again in separate blocks also by significance and correlation to the combined reading score. The remaining IVs (Consonant Blends/Digraphs, Decode: Patterns/Word Families, Letter Identification, Manipulation of Sounds, Matching Letters to Sounds, and Syllable Types: CVC, CVCe, R-Control) were not significant and were entered in two grouped blocks. The first grouped block contained Consonant Blends/Digraphs, Decode: Patterns/Word Families, Manipulation of Sounds, and Syllable Types: CVC, CVCe, R-Control as these variables did not violate the assumption of homoscedasticity. To minimize the chance of artificially masking any measureable effect on variance accounted for by grouped variables the remaining two variables, Letter Identification and Matching Letters to Sounds, were grouped in the final block as each violated the assumption of homoscedasticity. 
Findings and Results

\begin{tabular}{|c|c|c|c|c|c|c|c|c|c|}
\hline \multirow[t]{2}{*}{ Model } & \multirow[t]{2}{*}{$\mathrm{R}$} & \multirow{2}{*}{$\begin{array}{c}\mathrm{R} \\
\text { Square }\end{array}$} & \multirow{2}{*}{$\begin{array}{l}\text { Adjusted } \\
\text { R Square }\end{array}$} & \multirow{2}{*}{$\begin{array}{c}\text { Std. } \\
\text { Error of } \\
\text { the } \\
\text { Estimate }\end{array}$} & \multicolumn{5}{|c|}{ Change Statistics } \\
\hline & & & & & $\begin{array}{l}\text { R Square } \\
\text { Change }\end{array}$ & $\begin{array}{c}\mathrm{F} \\
\text { Change }\end{array}$ & df1 & $\mathrm{df} 2$ & $\begin{array}{l}\text { Sig. F } \\
\text { Change }\end{array}$ \\
\hline 1 (PA) & .695 & .484 & .483 & 12.111 & .484 & 504.804 & 1 & 539 & $.000 *$ \\
\hline $2(\mathrm{PI})$ & .738 & .544 & .543 & 11.389 & .061 & 71.510 & 1 & 538 & $.000 *$ \\
\hline 3 (VDD) & .786 & .618 & .616 & 10.430 & .074 & 104.502 & 1 & 537 & $.000 *$ \\
\hline 4 (DMSW) & .793 & .629 & .626 & 10.297 & .010 & 15.014 & 1 & 536 & $.000 *$ \\
\hline $\begin{array}{l}5(\mathrm{MoS} ; \\
\text { DPWF; } \\
\quad \text { CBD; ST) }\end{array}$ & .798 & .638 & .632 & 10.214 & .009 & 3.186 & 4 & 532 & $.013 *$ \\
\hline 6 (LI; MLtS) & .799 & .639 & .632 & 10.218 & .001 & .780 & 2 & 530 & .459 \\
\hline
\end{tabular}

Table 27 - Model Summary

* indicates significant

The pattern of results, as indicated by the model summary table above suggests that nearly half of the variability in the Combined Reading Survey with Goals RIT score is accounted for by the score on the Phonological Awareness skills checklist test. A change in $\mathrm{R}^{2}=.484$ indicates that $48.4 \%$ of the variance in the RIT score can be attributed to the score on the Phonological Awareness test when considered as the single independent variable in the regression. The score on the Phoneme Identification test contributed modestly to the prediction as did the score on Vowel Digraphs/Diphthongs, an additional $6.1 \%$ and $7.4 \%$ respectively when subsequently entered into the regression. At the end of each step both variables contributed statistically significantly to the combined reading score over and above the previously entered variables. The score on Decode: Multi-Syllable Words and the grouped scores on Manipulation of Sounds, Decode: Patterns/Word Families, Consonant Blends/Digraphs, and Syllable Types: CVC, CVCe, R-Control contributed to a lesser extent once entered at $1 \%$ and $.9 \%$ respectively. Once again their contributions after each step were statistically significant. Entering the 
Findings and Results

regression last the grouped scores on Letter Identification and Matching Letters to Sounds contributed only minimally, at .1\% (see Figure 31 below), and subsequently did not significantly improve the measure of variance. Thus there was no significant increase in predictability of the Combined Reading Survey with Goals RIT score by the addition of the scores on Letter Identification and Matching Letters to Sounds to the regression equation when differences in the prior eight skills scores had already been accounted for $(p=.459)$.

\section{Variance Accounted for in Reading Scores}

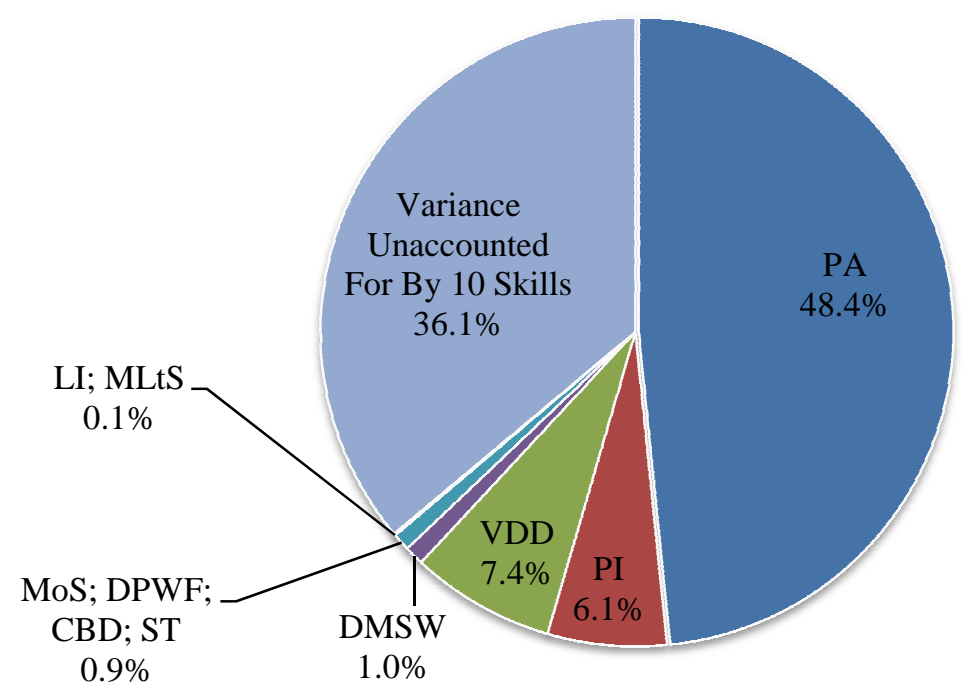

Figure 31 - Hierarchical Regression on Combined MPG Reading Survey with Goals Scores 
Findings and Results

\subsubsection{Segment 1 Reading Score (PhonAware, Phonic, ConPrnt)}

The order the independent variables were entered into the regression was similar to that for the regression on the Combined RIT score. However the third variable entered was Decode: Multi-Syllable Words. Given Vowel Digraphs/Diphthongs was no longer a significant variable in the multiple regression for this segment it was grouped with the other non-significant variables. The final set of variables entered was once again Letter Identification and Matching Letters to Sounds.

\begin{tabular}{|c|c|c|c|c|c|c|c|c|c|}
\hline \multirow[t]{2}{*}{ Model } & \multirow[t]{2}{*}{$\mathrm{R}$} & \multirow{2}{*}{$\begin{array}{c}\mathrm{R} \\
\text { Square }\end{array}$} & \multirow{2}{*}{$\begin{array}{l}\text { Adjusted } \\
\text { R Square }\end{array}$} & \multirow{2}{*}{$\begin{array}{c}\text { Std. } \\
\text { Error of } \\
\text { the } \\
\text { Estimate }\end{array}$} & \multicolumn{5}{|c|}{ Change Statistics } \\
\hline & & & & & $\begin{array}{l}\mathrm{R} \\
\text { Square } \\
\text { Change }\end{array}$ & $\begin{array}{l}\text { F } \\
\text { Change }\end{array}$ & df1 & $\mathrm{df} 2$ & $\begin{array}{l}\text { Sig. F } \\
\text { Change }\end{array}$ \\
\hline $1(\mathrm{PA})$ & .672 & .452 & .451 & 14.269 & .452 & 444.059 & 1 & 539 & $.000^{*}$ \\
\hline $2(\mathrm{PI})$ & .710 & .505 & .503 & 13.575 & .053 & 57.504 & 1 & 538 & $.000 *$ \\
\hline 3 (DMSW) & .740 & .548 & .546 & 12.977 & .044 & 51.731 & 1 & 537 & $.000 *$ \\
\hline $\begin{array}{l}4 \text { (VDD; } \\
\text { MoS; } \\
\text { DPWF; } \\
\text { CBD; ST) }\end{array}$ & .752 & .566 & .560 & 12.777 & .018 & 4.381 & 5 & 532 & $.001^{*}$ \\
\hline 5 (LI; MLtS) & .754 & .568 & .560 & 12.769 & .002 & 1.348 & 2 & 530 & .261 \\
\hline
\end{tabular}

Table 28 - Model Summary

* indicates significant

Similarly to the results when regressing on the Combined RIT score, nearly half, $45.2 \%$, of the variance in the Segment 1 Reading score is accounted for by the score on the Phonological Awareness skills checklist test. As was for the regression on the combined score the contribution of this variable was statistically significant. The score on the Phoneme Identification test and on the Decode: Multi-Syllable Words test each contributed modestly to the prediction when subsequently entered into the regression, an 
Findings and Results

additional $5.3 \%$ and $4.4 \%$ over and above the previous variables respectively (see Table 28). The contribution by each was statistically significant. The scores of the five grouped variables, Vowel Digraphs/Diphthongs, Manipulation of Sounds, Decode: Patterns/Word Families, Consonant Blends/Digraphs, and Syllable Types: CVC, CVCe, R-Control, in the fourth step contributed to a lesser extent, $1.8 \%$, but remained statistically significant. However, the grouped variable set Letter Identification and Matching Letters to Sounds accounted for only an additional $.2 \%$ of the variance in the Segment1 Reading score. The amount of change was not significant with $p=.261$ (see Figure 32 below).

\section{Variance Accounted for in Segment 1 Scores}

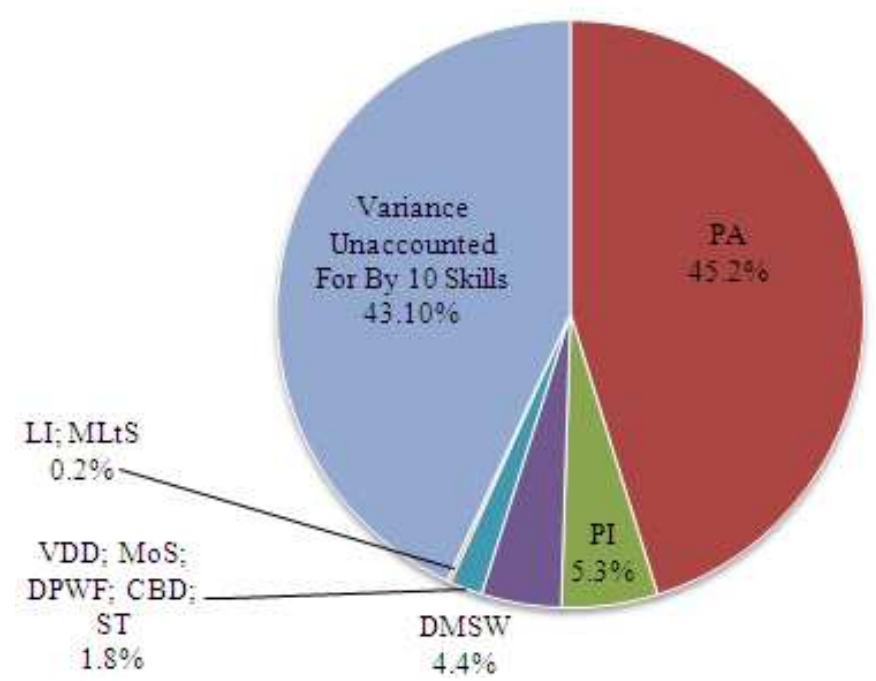

Figure 32 -Hierarchical Regression on Segment 1 Scores (PhonAware, Phonic, ConPrnt) 
Findings and Results

\subsubsection{Segment 2 Reading Score (Vocab, Comprehen, Writing)}

The order the independent variables were entered into the regression followed the same logic as was employed for the regression on the segment 1 analysis. In multiple regression on the segment 2 score, Phonological Awareness, Phoneme Identification, and Vowel Digraphs/Diphthongs were significant. The beta coefficients indicated Vowel Digraphs/Diphthongs had the greatest effect, followed by Phonological Awareness, and then by Phoneme Identification. As such this was the order of the first three variables. The forth set was grouped variables, Decode: Multi-Syllable Words, Vowel Digraphs/Diphthongs, Manipulation of Sounds, Decode: Patterns/Word Families, Consonant Blends/Digraphs, and Syllable Types: CVC, CVCe, R-Control. The final set was grouped variables Letter Identification and Matching Letters to Sounds.

\begin{tabular}{|c|c|c|c|c|c|c|c|c|c|}
\hline \multirow[t]{2}{*}{ Model } & \multirow[t]{2}{*}{$\mathrm{R}$} & \multirow{2}{*}{$\begin{array}{c}\mathrm{R} \\
\text { Square }\end{array}$} & \multirow{2}{*}{$\begin{array}{l}\text { Adjusted } \\
\text { R Square }\end{array}$} & \multirow{2}{*}{$\begin{array}{c}\text { Std. } \\
\text { Error of } \\
\text { the } \\
\text { Estimate }\end{array}$} & \multicolumn{5}{|c|}{ Change Statistics } \\
\hline & & & & & $\begin{array}{l}\text { R } \\
\text { Square } \\
\text { Change }\end{array}$ & $\begin{array}{l}\mathrm{F} \\
\text { Change }\end{array}$ & df1 & $\mathrm{df} 2$ & $\begin{array}{l}\text { Sig. F } \\
\text { Change }\end{array}$ \\
\hline 1 (VDD) & .712 & .507 & .506 & 11.629 & .507 & 555.151 & 1 & 539 & $.000 *$ \\
\hline $2(\mathrm{PA})$ & .755 & .569 & .568 & 10.883 & .062 & 77.421 & 1 & 538 & $.000 *$ \\
\hline $3(\mathrm{PI})$ & .766 & .587 & .585 & 10.663 & .018 & 23.360 & 1 & 537 & $.000 *$ \\
\hline $\begin{array}{l}4 \text { (DMSW; } \\
\text { MoS; } \\
\text { DPWF; } \\
\text { CBD; } \\
\text { ST) }\end{array}$ & .777 & .603 & .597 & 10.505 & .016 & 4.267 & 5 & 532 & $.001 *$ \\
\hline $\begin{array}{l}5(\mathrm{LI} ; \\
\mathrm{MLtS})\end{array}$ & .777 & .604 & .596 & 10.519 & .000 & .290 & 2 & 530 & .749 \\
\hline
\end{tabular}

Table 29 - Model Summary

* indicates significant 
Unlike the regression on both the combined score and on the segment 1 score, greater than half, 50.7\%, of the variance in the Segment 2 Reading score was accounted for by the score on the Vowel Digraphs/Diphthongs skills checklist test. As was for the prior regressions the contribution of this variable was statistically significant. The score on the Phonological Awareness test contributed modestly to the prediction when subsequently entered into the regression, an additional $6.2 \%$ over and above the variance accounted for by Vowel Digraphs/Diphthongs. The additional contribution by was statistically significant. The scores on Phoneme Identification and of the five grouped variables, Decode: Multi-Syllable Words, Manipulation of Sounds, Decode: Patterns/Word Families, Consonant Blends/Digraphs, and Syllable Types: CVC, CVCe, R-Control, in the fourth and fifth steps contributed to a lesser extent, and additional 1.8\% and $1.6 \%$ respectively. Each additional contribution remained statistically significant. However, the grouped variable set Letter Identification and Matching Letters to Sounds provided no additional account for the variability in the segment 2 score (see Figure 33 below). 
Findings and Results

\section{Variance Accounted for in Segment 2 Scores}

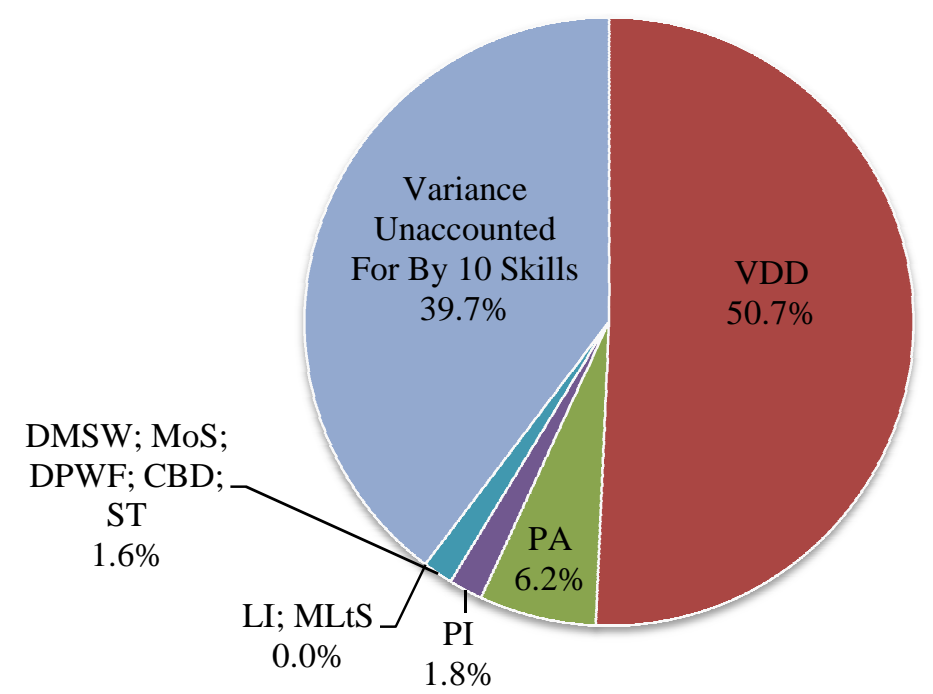

Figure 33 - Hierarchical Regression on Segment 2 Scores (Comprehen, Vocab, Writing)

\subsection{Mediation}

Mediation analysis was employed to determine if the Segment 1Reading Score (PhonAware, Phonic, ConPrnt) better predicted the Segment 2 Reading Score (Vocab, Comprehen, Writing) than the scores on the 10 skills checklist tests. Given the regression analysis revealed that segment 1 and segment 2 shared only 2 of the 10 skills tests as significant predictors, Phonological Awareness and Phoneme Identification, mediation will be based on these two variables alone. 
Findings and Results

\subsubsection{Analysis 1 - Segment 1 As Mediator}

The first mediation analysis employs the segment 1 score as the mediating variable with the segment 2 score as the dependent variable. This analysis answers the question, does the segment 1 score mediate the effects of Phonological Awareness and Phoneme Identification (the independent variables) on the segment 2 score.

STEP 1 - Regression analysis with Phonological Awareness and Phoneme Identification predicting the segment 2 score.

\begin{tabular}{|l|c|c|c|c|c|}
\hline \multirow{2}{*}{ Model } & \multicolumn{2}{|c|}{$\begin{array}{c}\text { Unstandardized } \\
\text { Coefficients }\end{array}$} & Standardized Coefficients & t & Sig. \\
\cline { 2 - 5 } & B & Std. Err & Beta & & \\
\hline 1 Constant & 138.856 & 1.809 & & 76.760 & .000 \\
\hline PA & .933 & .107 & .391 & 8.683 & .000 \\
\hline PI & .538 & .068 & .358 & 7.945 & .000 \\
\hline
\end{tabular}

Table 30 - Regression on Segment 2 score - STEP 1 $R^{2}=.484$

STEP 2 - Regression analysis with Phonological Awareness and Phoneme Identification predicting the segment 1 score.

\begin{tabular}{|l|c|c|c|c|c|}
\hline \multirow{2}{*}{ Model } & \multicolumn{2}{|l|}{$\begin{array}{l}\text { Unstandardized } \\
\text { Coefficients }\end{array}$} & Standardized Coefficients & $\mathrm{t}$ & Sig. \\
\cline { 2 - 5 } & $\mathrm{B}$ & Std. Err & Beta & & \\
\hline 1 Constant & 135.117 & 2.062 & & 65.526 & .000 \\
\hline PA & 1.190 & .123 & .429 & 9.717 & .000 \\
\hline PI & .585 & .077 & .335 & 7.583 & .000 \\
\hline
\end{tabular}

Table 31 - Regression on Segment 1 score - STEP 2 $\mathbf{R}^{2}=.505$ 
Findings and Results

STEP 3 - Regression analysis with the segment 1 score predicting the segment 2 score.

\begin{tabular}{|l|c|c|c|c|c|}
\hline \multirow{2}{*}{ Model } & \multicolumn{2}{|l|}{$\begin{array}{l}\text { Unstandardized } \\
\text { Coefficients }\end{array}$} & Standardized Coefficients & $\mathrm{t}$ & Sig. \\
\cline { 2 - 4 } & $\mathrm{B}$ & Std. Err & Beta & & \\
\hline 1 Constant & 48.437 & 3.772 & & 12.841 & .000 \\
\hline Segment1 & .710 & .021 & .826 & 34.009 & .000 \\
\hline
\end{tabular}

Table 32 - Regression on Segment 2 with Segment 1 - STEP 3

$\mathbf{R}^{2}=.682$

STEP 4 - Regression analysis with Phonological Awareness, Phoneme Identification, and the segment 1 score predicting the segment 2 score.

\begin{tabular}{|l|c|c|c|c|c|}
\hline \multirow{2}{*}{ Model } & \multicolumn{2}{|l|}{$\begin{array}{l}\text { Unstandardized } \\
\text { Coefficients }\end{array}$} & Standardized Coefficients & $\mathrm{t}$ & \multirow{2}{*}{ Sig. } \\
\cline { 2 - 4 } & $\mathrm{B}$ & Std. Err & Beta & & \\
\hline 1 Constant & 61.046 & 4.093 & & 14.913 & .000 \\
\hline Segment1 & .576 & .029 & .670 & 20.165 & .000 \\
\hline PA & .248 & .088 & .104 & 2.814 & .005 \\
\hline PI & .201 & .054 & .134 & 3.735 & .000 \\
\hline
\end{tabular}

Table 33 - Regression on Segment 2 score with PA, PI, and Segment1 - STEP 4 $\mathbf{R}^{2}=.707$

Mediation revealed that Segment 1 (PhonAware, Phonic, ConPrnt) partially mediated both Phonological Awareness and Phonemic Identification (see Tables 30-33 above). P values for each remained significant at .005 and .000 respectively. The B weight was reduced from .933 to .248 on Phonological Awareness. This means that for every point higher a student scores on the Phonological Awareness test their corresponding segment 2 RIT score increases by approximately a quarter rather than almost a full RIT point holding both the score on the Segment1 test and the score on the 
Findings and Results

Phoneme Identification test constant. As was the case with Phonological Awareness the B weight was reduced on Phonemic Identification as well from .538 to .201. This means that for every point higher a student scores on the Phoneme Identification test their corresponding segment 2 RIT score increases by approximately a fifth rather than a half of a RIT point holding both the score on the Segment1 test and the score on the Phonological Awareness test constant. Additionally, the inclusion of the segment 1 score increased the overall variance accounted for $\left(\mathrm{R}^{2}\right)$ from $48.4 \%$ to $70.7 \%$.

\subsubsection{Analysis 2-Segment 2 As Mediator}

Mediation analysis was employed a second time to determine what effect the Segment 2 Reading Score (Vocab, Comprehen, Writing) had on the variance accounted for by both Phonological Awareness and Phoneme Identification on the Segment 1 Reading Score (PhonAware, Phonic, ConPrnt).

STEP 1 - Regression analysis with Phonological Awareness and Phoneme Identification predicting the segment 1 score.

\begin{tabular}{|l|c|c|c|c|c|}
\hline \multirow{2}{*}{ Model } & \multicolumn{2}{|l|}{$\begin{array}{l}\text { Unstandardized } \\
\text { Coefficients }\end{array}$} & Standardized Coefficients & \multirow{2}{*}{ Sig. } \\
\cline { 2 - 4 } & $\mathrm{B}$ & Std. Err & Beta & & \\
\hline 1 Constant & 135.117 & 2.062 & & 65.526 & .000 \\
\hline PA & 1.190 & .123 & .429 & 9.717 & .000 \\
\hline PI & .585 & .077 & .335 & 7.583 & .000 \\
\hline
\end{tabular}

Table 34 - Regression on Segment 1 score - STEP 1

$\mathbf{R}^{2}=.505$ 
Findings and Results

STEP 2 - Regression analysis with Phonological Awareness and Phoneme Identification predicting the segment 2 score.

\begin{tabular}{|l|c|c|c|c|c|}
\hline \multirow{2}{*}{ Model } & \multicolumn{2}{|l|}{$\begin{array}{l}\text { Unstandardized } \\
\text { Coefficients }\end{array}$} & Standardized Coefficients & $\mathrm{t}$ & Sig. \\
\cline { 2 - 5 } & $\mathrm{B}$ & Std. Err & Beta & & \\
\hline 1 Constant & 138.856 & 1.809 & & 76.760 & .000 \\
\hline PA & .933 & .107 & .391 & 8.683 & .000 \\
\hline PI & .538 & .068 & .358 & 7.945 & .000 \\
\hline
\end{tabular}

Table 35 - Regression on Segment 2 score - STEP 2 $\mathbf{R}^{2}=.484$

STEP 3 - Regression analysis with the segment 2 score predicting the segment 1 score.

\begin{tabular}{|l|c|c|c|c|c|}
\hline \multirow{2}{*}{ Model } & \multicolumn{2}{|c|}{$\begin{array}{c}\text { Unstandardized } \\
\text { Coefficients }\end{array}$} & Standardized Coefficients & $\mathrm{t}$ & Sig. \\
\cline { 2 - 4 } & $\mathrm{B}$ & Std. Err & Beta & & \\
\hline 1 Constant & 10.573 & 4.993 & & 2.118 & .035 \\
\hline Segment2 & .961 & .028 & .826 & 34.009 & .000 \\
\hline
\end{tabular}

Table 36 - Regression on Segment 1 with Segment 2 - STEP 3 $R^{2}=.682$

STEP 4 - Regression analysis with Phonological Awareness, Phoneme Identification and the segment 2 score predicting the segment 1 score.

\begin{tabular}{|l|c|c|c|c|c|}
\hline \multirow{2}{*}{ Model } & \multicolumn{2}{|l|}{$\begin{array}{l}\text { Unstandardized } \\
\text { Coefficients }\end{array}$} & Standardized Coefficients & $\mathrm{t}$ & Sig. \\
\cline { 2 - 5 } & $\mathrm{B}$ & Std. Err & Beta & & \\
\hline 1 Constant & 31.214 & 5.383 & & 5.799 & .000 \\
\hline Segment2 & .748 & .037 & .643 & 20.165 & .000 \\
\hline PA & .492 & .099 & .177 & 4.983 & .000 \\
\hline PI & .183 & .062 & .105 & 2.966 & .003 \\
\hline
\end{tabular}

Table 37 - Regression on Segment 1 score with PA, PI, and Segment2 - STEP 4 $\mathbf{R}^{2}=.707$ 
Findings and Results

As was the case with segment 1 , segment 2 also partially mediated the effects of both Phonological Awareness and Letter Identification (as indicated in Tables 34-37). P values for each remained significant at .000 and .003 respectively. The B weight was reduced from 1.190 to .492 on Phonological Awareness. This means that for every point higher a student scores on the Phonological Awareness test their corresponding segment 1 RIT score increases by approximately a half rather than just over a full RIT point holding both the score on the segment 2 test and the score on the Phoneme Identification test constant. As was the case with Phonological Awareness the B weight was reduced on Phonemic Identification from .585 to .183 . This means that for every point higher a student scores on the Phoneme Identification test their corresponding segment 1 RIT score increases by approximately a fifth rather than a half of a RIT point holding both the score on the segment 2 test and the score on the Phonological Awareness test constant. Variance accounted for increased from $50.5 \%$ to $71.8 \%$.

\subsection{Summary of Results and Findings}

Multiple regression revealed moderate to high relationships between 8 of the 10 decoding skills (Consonant Blends/Digraphs, Decode: Patterns/Word Families, Decode: Multi-Syllable Words, Manipulation of Sounds, Phoneme Identification, Phonological Awareness, Syllable Types: CVC, CVCe, R-Control, and Vowel Digraphs/Diphthongs) and each of the 3 reading scores (Combined Reading Survey with Goals RIT Score, Segment 1 Reading Score - PhonAware, Phonic, ConPrnt, Segment 2 Reading Score - 
Findings and Results

Vocab, Comprehen, Writing). Weak relationships were found between Letter Identification and Matching Letters to Sounds and reading scores. The 10 skills as a group were stronger predictors of the Combined Reading score and the segment 2 score than of the segment 1 score. Finally, multiple regression indicated differences in significant predictive variables identified for segment 1 as compared to segment 2 .

Hierarchical regression indicated the greatest variance accounted for in each of the reading scores was attributed to the predictor variable entered first into each regression. Subsequent variables (or groups of variables) exhibited diminishing accountability in variance. Regressions on each of the three reading scores indicated that grouped predictive variables Letter Identification and Matching Letters to Sounds accounted for no additional significant variance in scores.

Mediation analysis revealed that segment 1 partially mediated the variance accounted for by the Phonological Awareness and Phoneme Identification skills in the segment 2 score. It also revealed that segment 2 partially mediated the variance accounted for in the segment 1 score by the aforementioned skills. Interpretation and implications of the findings are elaborated on within the discussion chapter. 
Discussion

\section{Chapter 5 - Discussion}

This chapter provides a review of the purpose for the study. It details the types of analyses used, why, what the analyses revealed, and what the implications were. Also provided are actionable steps that teachers, administrators, and even government can take to facilitate impactful, targeted instruction that may help all early learners achieve their literacy goals. The chapter closes with the limitations of the current research as well as implications for future research.

The purpose of this study was to examine what the level of proficiency in each of the decoding skills tells us about a students' overall performance/ability to read. Looking at the data from a predictive standpoint on several aspects of decoding other than phonemic awareness alone moves the research community further along that avenue. Furthermore, examining the individual segments, Segment1 (PhonAware, Phonic, ConPrnt), and Segment2 (Vocab, Comprehen, Writing), of the reading assessment provides a level of granularity that delivers greater insight as compared to regressing on the combined reading assessment score alone. The other perspective in which to examine the data is in understanding the relationship among the decoding skills. Understanding these correlations provides the means by which educators may target specific instruction for individuals and groups of students.

Multiple regression analysis was the first step toward that end. The relationship between each of the decoding skills when paired with the combined reading score tells us 
Discussion

both the strength between the variables and the direction. A positive regression slope indicates a gain in the predicting variable corresponds with a gain in the predicted variable and a deficit in the predicting variable corresponds to a deficit in the predicted variable (i.e. the variables are either both positive or both negative). Conversely a negative regression slope indicates the predicting and predicted variables have opposite signs (i.e. a gain in one corresponds to a deficit in the other). The regression on the combined reading score highlighted three important issues:

1) The correlations among many of the independent variables were moderate to high. Moderate to high correlations among variables tend to overstate the importance of the contribution made by variables individually because it doesn't account for the covariance among variables.

2) Two of the variables were skewed (i.e. more of the data points fell to one end of the distribution). This explains that their insignificant contribution was as a result of the majority of students scoring at one end of the scale and not because the skill being assessed is unimportant.

3) Of the 10 decoding skills (Consonant Blends/Digraphs, Decode: Patterns/Word Families, Decode: Multi-Syllable Words, Letter Identification, Manipulation of Sounds, Matching Letters to Sounds, Phoneme Identification, Phonological Awareness, Syllable Types: CVC, CVCe, R-Control, and Vowel Digraphs/Diphthongs) only 4 of them 
Discussion

(Phonological Awareness, Phoneme Identification, Vowel Digraphs/Diphthongs, and Decode Multi-Syllable Words) were statistically significant.

The practical application of the regression results stems from the fact that generally speaking, higher scores on decoding skills corresponded to higher scores in reading. The exception to this was in the assessment of Letter Identification and Matching Letters to Sounds. For these two skills the study provided empirical evidence indicating both letter identification and matching letters to sounds to be foundational skills (Honig, Diamond, and Gutlohn 2000) with $92 \%$ of the sample correctly identifying at least $96 \%$ of the letters in both upper and lower cases, and $86 \%$ of the students proficient at matching letters to sounds. Identifying these skills as foundational based on the data suggest these are skills that require mastery, and once mastered it is unnecessary to continually review them.

A review of the findings indicated that students exhibiting proficiency or mastery of the Letter Identification skill scored between 12 and 30 RIT points higher (140-219) on the Combined Reading test, at the low and high ends of the distribution respectively, as compared to students not proficient (128-189) or who had not mastered the skill. To put this into perspective for the reader, a student proficient on Letter Identification scoring the lowest for the proficient subset of students (140 RIT) would be considered comparable to the reading ability associated with the $1^{\text {st }}$ percentile for first grade students. A student that was not proficient and also scored the lowest (128 RIT) for the not 
Discussion

proficient subset of students, would be 10 RIT points below the reading ability associated with kindergarten students in the $1^{\text {st }}$ percentile. Students with the highest reading scores in both the proficient and the not proficient subsets exhibited greater disparity with proficient students scoring higher than the $99^{\text {th }}$ percentile of second graders (219 RIT); whereas, the not proficient students scored a full 30 RIT points lower (189 RIT), which is about the $50^{\text {th }}$ percentile of second grade students. Comparisons on mastery of Matching Letters to Sounds yielded similar results.

Additionally, the regression revealed correlated skills. Providing this type of information helps educators better understand the reading test data on their students. It tells them that when combined with other data on like skills the effect is not necessarily additive. Without knowledge regarding the extent to which discrete skills correlate to one another educators may be led to make erroneous assumptions. Suppose you are a teacher and you are given information indicating scores on Phonological Awareness tests account for $48.4 \%$ of the variance in reading scores and scores on Phoneme Identification tests account for $45.5 \%$ of the variance you may make the assumption depicted by Figure 34. 
Discussion

\section{Variance Accounted for in Reading Scores}

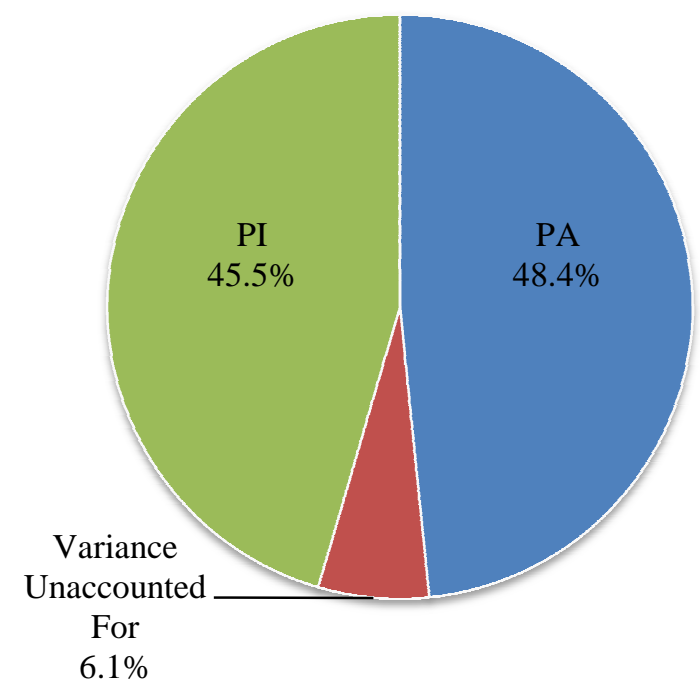

Figure 34 - Improperly Reported Variance Accounted for in Reading Scores

The actual variance accounted for in reading scores by considering both scores on Phonological Awareness and Phoneme Identification taking into account the high correlation between these discrete skills (.726) paints a vastly different picture (see Figure 35 on the following page). 
Discussion

\section{Variance Accounted for in Reading Scores}

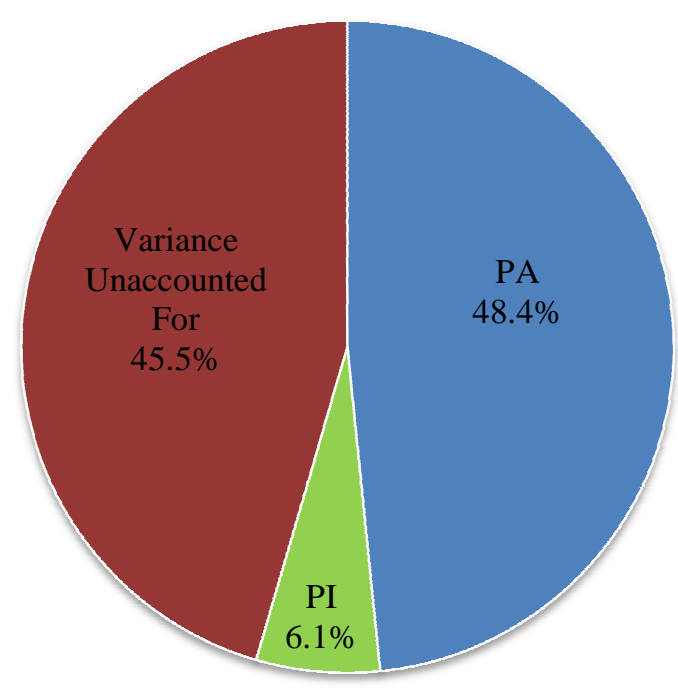

Figure 35 - Variance Accounted for in Reading Scores (with correlation taken into account)

*Note: PA contributes to a greater extent because it was entered into the regression first. Had PI been entered first it would have contributed $45.5 \%$ with PA contributing an additional $9 \%$.

The combined variance accounted for in reading scores attributable to knowledge of a student's performance on phonological awareness and phoneme identification based on Figure 34 is $93.9 \%$ as compared to $54.5 \%$ when based on Figure 35 . The type of instruction or intervention provided to a student varies greatly based on which chart a teacher considers.

Finally, the multiple regression revealed the skills that were statistically significant and those that were not. Studies have indicated the importance of 
Discussion

phonological and phonemic awareness (Chard \& Dickson 1999, NRP 2000, Cassady, Smith, \& Huber 2005) and this study provided empirical evidence to further support their findings. However, the present study extended previous research by examining additional skills and provided new information that may be utilized for targeted intervention in conjunction with what the teacher already knows about the students' ability.

Hierarchical regression was necessary once covariance was identified in order to determine the extent to which the importance of combined predictive variables might be overstated. The data indicated skill areas having the greatest effect on reading and segment scores. When a student seems to be struggling with comprehension the data suggests that examining a student's ability with vowel digraphs and diphthongs may be a good place to start. Should a student score lower on decoding segments of an assessment, looking at proficiency in phonological awareness may be a good starting place. Although the information gleaned from this analysis may be insufficient on its own to definitively indicate issues a student may have with their reading ability, this information may supplement what a teacher already knows about his or her students.

Discrete skills for reading can be likened to basketball drills for a child learning to play basketball. The drills are necessary to learn the basics of basketball but until the child has an opportunity to play the game and begins to apply the skills appropriately within the context on the game he will not fully understand nor successfully execute play. 
Discussion

Students must also have the opportunity to practice their skills in the context of reading text. Like reading, when it is no longer necessary for the student to sound out the letters and words and attention shifts to saying the words and reading for meaning, the child learning basketball begins to automatically apply the correct drill at the correct time. Still all of this is necessary for proficient reading, or proficient basketball play, but not sufficient. For a student to become a proficient reader he must be fluent in his reading. That is, when he reads the words he does so with expression rather than in the choppy, robotic manner that is common with beginning readers. For the child playing basketball he must also develop fluency. He too must understand how to transition from one play to the next.

The mediation analysis highlighted an important factor when assessing reading ability. When assessing individual skills within the domain of reading only the discrete components are assessed and not the context in which those discrete components appear. Thus the Segment 1 (PhonAware, Phonic, ConPrnt) test score partially mediated both Phonological Awareness and Phoneme Identification while accounting for additional variance explained in the Segment 2 (Comprehen, Vocab, Writing) test score. The same was true when examining mediation by the segment 2 score. Segment 2 (Comprehen, Vocab, Writing) partially mediated both Phonological Awareness and Phoneme Identification while accounting for additional variance explained in the Segment 1 (PhonAware, Phonic, ConPrnt) test score. These findings provide empirical evidence indicating that the skills necessary for proficient reading are not hierarchical in nature 
Discussion

because the analysis indicated partial mediation regardless of which segment score was used as the mediator.

\subsection{Limitations}

The limitations for this research were that there were no discrete skills specifically assessing comprehension, and the tests administered to these students did not assess automaticity. Absent data for discrete measures of comprehension skills prohibited further testing the interactive theory of reading. Although analysis of this type of data would not prove the theory, such analysis could provide further support for the theory or raise questions. Having data on automaticity for each question presented to the student during the assessment would provide additional information regarding his level of proficiency within a skill. If a student's response is automatic that tells us that the student doesn't have to expend effort on identifying the letter/sound/word and is further in his reading ability than the student who must make the conscious effort to do the same task.

The content assessed by test questions in the Segment 1 (PhonAware, Phonic, ConPrnt) test and Segment 2 (Comprehen, Vocab, Writing) test were not aligned to specific state content standards. Instead the content was aligned based on standards set forth by the International Reading Panel, National Council of Teachers of English, Center for the Improvement for Early Reading Achievement, the National Research Council, and 
Discussion

the U.S. Department of Education Institute of Educational Sciences. As such the ability to generalize to other assessments could be called into question. Future research to establish the relationship with other assessments in this area is called for.

\subsection{Implications for Future Research}

Left for subsequent research is further decomposing the data by grade. In this sample the number of kindergarteners was insufficient $(\mathrm{N}=49)$ to be considered on its own for analysis, and there was no data indicating whether kindergarten students attended half day, in the morning or afternoon, or if they attended full day. Analyses including this data may indicate patterns of learning as a student progresses from kindergarten through second grade.

This study could be further extended to include additional attributes such as gender, ethnicity, and socio-economic status. Inclusion of these attributes would provide similarities and/or disparities among cohorts. Such findings may further support this study or provide additional insight in learning patterns.

\subsection{Summary of Discussion}

In summation, decoding by itself does not sufficiently predict the reading ability of students in kindergarten, first, and second grades. This in and of itself is no 
Discussion

revelation to veteran teachers. What is paramount is being cognizant of the variance accounted for in reading scores by what one knows about decoding. Knowledge of this data provides teachers with additional information to help them zero in on difficulties students may be having as they advance in their literacy. Addressing specific stumbling blocks for students can alleviate the frustration the student may be experiencing and further facilitate their engagement in the curriculum. Administrators can make better informed decisions when it comes to targeting ever diminishing budget dollars. Despite the well intentioned legislation of No Child Left Behind student learning has been woefully flat in the U.S. even when measured against an arbitrary benchmark, such as measures of standards set by state departments of education. Perhaps additional studies that decompose other domains within education will provide greater insight for teachers and administrators to further improve their student's academic growth overall. Finally, it would be helpful if government were to adopt a macro position in education, providing guidelines and education dollars for student growth rather than holding schools accountable for benchmarks set by state governments that are inconsistent when compared across all states. 


\section{References}

Allignton, R.L. (2005). Ideology Is Still Trumping Evidence [Electronic version]. Phi Delta Kappan, 86(6), 462-468.

Altwerger, B., Edelsky,C., Flores, B. M. (Nov. 1987). Whole Language: What's New [Electronic version]? The Reading Teacher, 41(2), 144-154.

Baron, R. M., \& Kenny, D. A. (1986). The Moderator-Mediator Variable Distinction in Social Psychological Research: Conceptual, Strategic, and Statistical Considerations. Journal of Personality and Social Psychology, 51, 1173-1182.

Braunger, J., \& Lewis, J. P. (2006). Building a Knowledge Base in Reading. Second Edition. Newark, DE. International Reading Association.

Cassaday, J.C., Smith, L.L., Huber, L.K. (2005). Enhancing Validity in Phonological Awareness Assessment Through Computer-Supported Testing [Electronic version]. Practical Assessment Research and Evaluation, 10(18), 1-13.

Chall, J. S. (1983). Learning to read: The great debate.Third Edition. New York, NY. McGraw-Hill. 
Chall, J.S. (1997). Are Reading Methods Changing Again [Electronic version]? Annals of Dyslexia. 47, 257-263.

Chard, D.J., \& Dickson, S.V. (1999). Phonological Awareness: Instructional Assessment Guidelines [Electronic version]. Retrieved March 2, 2010, from http://www.ldonline.org/article/6254

Crowe, L.K. (2005). Comparison of Two Oral Reading Feedback Strategies in Improving Reading Comprehension of School-Age Children with Low Reading Ability [Electronic version]. Remedial and Special Education, 26 (1), 32-42.

Currier , L. B., \& Duguid, O. C. (1916). Phonics or No Phonics [Electronic version]? The Elementary School Journal, 17(4), 286-287.

Currier, L. B. (1923). Phonics and No Phonics [Electronic version]. The Elementary School Journal, 23(6), 448-452.

Dolch, E. W., \& Bloomster, M. (1937). Phonic Readiness [Electronic version]. The Elementary School Journal, 38(3), 201-205.

Goodman, K.S., \& Goodman, Y.M. (1976). Learning to Read is Natural [Electronic version]. Pittsburg Univ., PA. Learning Research and Development Center. 
Goodman , K.S. (1987). Acquiring Literacy Is Natural: Who Skilled Cock Robin [Electronic version]? Theory into Practice, 26, 368-373.

Goodman , K.S. (1989). Whole-Language Research: Foundations and Development [Electronic version]. The Elementary School Journal, 90(2), 207-221.

Green, S.B. (2008). Using SPSS for Windows and Macintosh: Analyzing and Understanding Data. Fifth Edition. Upper Saddle River, NJ. Pearson Prentice Hall.

Honig, B., Diamond, L., Gutlohn, L. (2000). Teaching Reading:Sourcebook for Kindergarten Through Eighth Grade. Novato, CA. Arena Press.

Ingebo, G.S. (1997). Probability in the Measure of Achievement: Rasch Measurement. Chicago, IL. MESA Press.

LaBerge, D., \& Samuels, S.J. (1974). Toward a Theory of Automatic Information Processing in Reading [Electronic version]. Cognitive Psychology, 6, 293-323.

Moats, L. C. (2000). Speech to Print: Language Essentials for Teachers. Baltimore, MD. Paul H. Brooks Publishing Co. 
Morgan, E. F. Jr., \& Light, M. (1963). A Statistical Evaluation of Two Programs of Reading Instruction [Electronic version]. The Journal of Educational Research, 57(2), 99-101.

National Institute of Child Health and Human Development. (2000). Report of the National Reading Panel. Teaching children to read: an evidence-based assessment of the scientific research literature on reading and its implications for reading instruction: Reports of the subgroups (NIH Publication No. 00-4754). Washington, DC: U.S. Government Printing Office.

Noah Webster. (2010, April 10) In Wikipedia, the free encyclopedia. Retrieved April 10, 2010, from http://en.wikipedia.org/wiki/Noah_Webster

Northwest Evaluation Association. (2008). Technical Manual for Measures of Academic Progress for Primary Grades. Lake Oswego, OR.

Stahl, S.A., \& Miller, P.D. (1989). Whole Language and Language Experience Approaches for Beginning Reading: A Quantitative Research Synthesis [Electronic version]. Review of Educational Research, 59(1), 87-116. 
References

Stanovich, K.E. (1980). Toward an Interactive-Compensatory Model of Individual Differences in the Development of Reading Fluency [Electronic version]. Reading Research Quarterly, 16 (1), 32-71.

Tabachnick, B.G., \& Fidell, L.S. (2007). Using Multivariate Statistics. Fifth Edition.

Boston, MA. Pearson Education, Inc.

Watson, D.J. (1989). Defining and Describing Whole Language. The Elementary School Journal, 90(2), 129-141.

Weaver C. (2002). Reading Process \& Practice. Third Edition. Portsmouth NH. Heinemann. 